\title{
3. Banditentum im Römischen Reich und in Isaurien
}

\author{
Piraten suchten schon immer die Seefahrer heim, \\ ebenso wie es auch die Räuber mit den Landbewohnern \\ zu tun pflegten. Es gibt ja keine Zeit, in der solche Verbrechen \\ unbekannt waren, und es dürfte damit wohl auch kein Ende nehmen, \\ solange die menschliche Natur die gleiche bleibt. ${ }^{1}$
}

$\mathrm{Da} \beta$ es angesichts des hier festgestellten hohen Romanisierungs- und Urbanisierungsgrades in Isaurien dennoch zu den in den vorigen Kapiteln geschilderten großräumigen Aufständen und Unruhen der Isaurier kam, wirft die grundsätzliche Frage nach deren tieferen Ursachen sowie deren unterschiedliche Interpretation als politisch, ökonomisch oder ethnisch motiviert: ${ }^{2}$ Waren es lediglich fortgesetzte Aktionen einfacher Banditen, wie in der antiken Historiographie dargestellt, oder verbarg sich ein politischer, in der Stammes-Idiosynkrasie begründeter Widerstand gegen Rom darin? Waren die Aufstände zu jedem Zeitpunkt ähnlicher Natur, oder sollte in ihrer Betrachtung eher, im Hinblick auf unterschiedliche Rahmenbedingungen, differenziert werden? ${ }^{3}$ Zur Klärung der Art des isaurischen Widerstands und der antiken Einschätzung des Phänomens soll hier zunächst die zeitgenössische Reaktion auf das Banditenwesen allgemein diskutiert werden.

\subsection{Allgemeine Überlegungen zum Banditentum im Römischen Reich}

Nach der communis opinio stellen die auf das antike Räuberwesen bezogenen Quellen oft weniger die Realität als deren durch die Phantasie der Autoren gebrochene Reflexionen oder gar phantasievolle eigene Konstrukte dar. Das Konzept des ,edlen Räubers" der aus politischen Gründen handelt, in der Literatur und zuweilen auch in der Geschichtsschreibung, fungiert dabei geradezu als oppositionelles Wunschbild zur Gegenwart. Oftmals sind die Vorkommnisse in mythologischen Zusammenhang

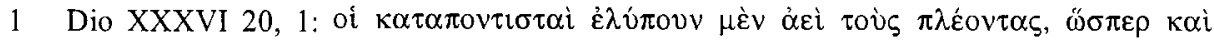

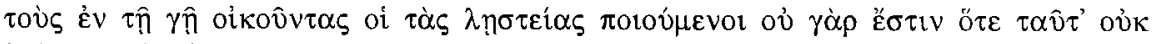

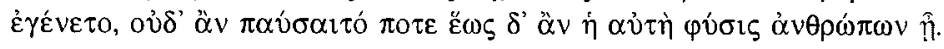

2 Vgl. Rougé (1966) 300, der zwar die Alternativen eines politischen Separatismus (nach RostofzeFF, der gegen die Klassenkampf-Theorie sowjetischer Historiker argumentierte) oder eines Überlebens des lokalen Tribalismus nennt, sich jedoch nicht entscheidet.

3 Vgl, die Kritik von LENSKI (1999a) 417f. an der mangelnden Differenzierung der einzelnen Aufstände durch die bisherige Forschung. 
gerückt, wie beim Goldenen Esel des Apuleius. ${ }^{4}$ Auf die historische Realität bezogen erweist sich jedoch die Annahme einer rein politischen statt einer vorrangig ökonomischen Motivation des antiken Banditentums als Spekulation: Oftmals erhielten die ursprünglich ökonomisch motivierten Aufstände erst durch die militärische Reaktion der angegriffenen römischen Ordnungsmacht politischen Charakter. Dieser Sachverhalt läßt sich gerade an der Geschichte der isaurischen Aufstände demonstrieren. ${ }^{5}$ Zunächst sollen jedoch die Begriffe im Einzelnen definiert werden, um einem Verständnis der zeitgenössischen Reaktion auf die isaurischen Raubzüge näherzukommen.

\subsubsection{Die römische Definition des latrocinium}

und die daraus folgende Legitimation von staatlicher Gewalt

In den römischen Gesetzestexten wird nahezu jede Art von gewalttätiger Opposition gegen die etablierte staatliche Autorität als latrocinium bezeichnet. Weil in der Antike eine klare Trennung zwischen Zivil- und Strafrecht nicht gegeben war, kam es zu einer bedeutend weiter gefaßten Definition des Banditen als im modernen Staat: Alle Banditen wurden als außerhalb des Gesetzes stehend (,outlaws") behandelt, schließlich stellten sich diese selbst außerhalb des Völkerrechts, das in der Antike die staatliche Gewalt begründete. ${ }^{6}$ Banditen genossen in Strafprozessen keinerlei Verteidigungs- oder Appellationsrechte, und Eheschließungen waren null und nichtig, falls ein Ehepartner des latrocinium bezichtigt wurde. Dabei erfolgte die Abgrenzung zwischen Staatsfeinden und Banditen über den Akt der Kriegserklärung:

4 Apuleius Madaurensis, Metamorphoses, ed. Rudolf HELM, Leipzig 1907, ND 1968. Zum antiken Räuberwesen jüngst GRÜNEWALD (1999); umfassend, von Apuleius ausgehend RIESS (2001); zuvor für die Spätantike MACMULlEN (1966) 255-268; allgemeine Theorien bespricht SHAW (1984) unter dem Aspekt einer im Verlauf dieses Kapitels zu diskutierenden These, in Auseinandersetzung mit der ,social bandit“-These von HoBSBAWM ( $\left({ }^{2} 1972\right)$; SÜNSKES THOMPSON (1990) 190-207, 191, Anm. 177 (Forschungsliteratur); zu Räubern und Barbaren in der römischen Historiographie BuRIAN (1984). Die Quellen sind zusammengestellt bei Ivo PFAFF, s.v. 'latrocinium', $R E$ XII 1 (1924) 978-980; ergänzt durch Gunnar Mick wiTz, s.v. 'Straßenraub', RE Suppl. VII (1940) 1242; Ettore DE RUGGIERo/ G. BARBIERI, s.v. 'Iatrones', Dizionario epigrafico 4 (1942) 460-466.

5 So auch GRÜNEWALD (1999) 236. Dagegen sehen SHAw (1990) und, trotz Gegnerschaft, LENSKI (1999a) die Ursache der isaurischen Aufstände noch am ehesten als politisch im Sinne einer generellen Ablehnung der römischen Herrschaft an.

6 Gai. inst. I 1. 
„Hostes sind jene, denen das römische Volk öffentlich den Krieg erklärt hat oder die dem römischen Volk den Krieg erklärt haben, die übrigen werden Räuber oder Plünderer genannt." 7

Das heißt: Dic latrones und praedones haben zwar nicht dem römischen Volk publice den Krieg erklärt, streben aber aus Sicht des Gesetzgebers ebenso wie äußere Feinde die Vernichtung des Staatswesens an und sind aus diesem Grund wie die hostes zu bekämpfen. Anders als bei diesen ist jedoch die Möglichkeit eines Friedensvertrags zwischen Staat und Räubern ausgeschlossen. In diesem Sinne wurde auch den isaurischen Banditen mit der Klassifizierung als „Räuber" in den zu kriegerischen Auseinandersetzungen angewachsenen Konflikten im 3. und 4. Jahrhundert die Anerkennung als völkerrechtliche Subjekte verwehrt. ${ }^{8}$ Überhaupt wurde aufgrund der Konnotation Räuber/Staatsfeind der Terminus latro von römischen Rhetoren gegen politische Gegner und Usurpatoren als literarische Folie für den Tyrannen angewandt, um so deren Verhalten als staatsfeindlich zu brandmarken. ${ }^{9}$

Umgekehrt wurden große Staatswesen in der antiken Literatur immer wieder mit Räuberbanden verglichen, um deren Legitimation für eine übergeordnete Rechtssetzung in Frage zu stellen. Dieser topische Vergleich ist wohl ebenso alt wie komplexe staatliche Gebilde und zeigt die kontinuierliche Diskussion um die Ursprünge der staatlichen Gewalt auf. Sie beginnt beim biblischen Nimrod, dem sagenhaften Gründer des assyrischen Großreichs, und setzt sich über die bei Cicero erstmals belegte und von Augustinus wiederholte Geschichte von Alexander und dem Seeräuber fort. Nach Meinung eines von Alexander gefangenen und zur Rede gestellten Seeräubers seien Staaten letztendlich nichts anderes als große Räuberbanden, und diese seien umgekehrt nichts anderes als kleine Staaten. ${ }^{10}$

7 Dig. 49, 15, 24: Hostes sunt, quibus bellum publice populus Romanus decrevit vel ipsi populo Romano: ceteri latrunculi vel praedones appellantur; s. auch Dig. 50, 16, 118; vgl. MaCMUlLEN (1966) 255; ShaW (1984) 6. 21; Grunewald (1999) $24 f$.

8 Vgl. Riess (2001) 109, Anm. 107.

9 Beispielsweise von Cicero gegen Clodius, Cic. Mil. 55: Quia non semper viator a latrone, non numquam etiam latro a viatore occiditur; quia, quamquam paratus in imparatos Clodius, ipse Clodius tamen mulier inciderat in viros. Weitere Belege für den politischen Gebrauch von latro bei Ilona OPELT, Die lateinischen Schimpfwörter und verwandte sprachliche Eigenschaften. Eine Typologie. Heidelberg 1965, 29, 47, 132-137, 165-169, 179, 192 ff., 209, 235, 263; vgl. SEECK (1921) V 23; OrMERod (1924) passim; Ramsay MACMullen, 'The Roman concept Robber-Pretender' in: RIDA 10 (1963), 221-225; Ders. (1966) 224; MINOR (1971) 4; BURIAN (1984); SHAW (1984) 44 ff.; SÜNSKES THOMPSON (1990) 192, 197.

10 Augustin. CD IV 4 aus Cic. rep. III 24: Nam cum quaereretur ex eo, quo scelere inpulsus mare haberet infestum uno myoparone, „Eodem ", inquit, , quo tu orbem terrae "; wieder bei Jean Bodn, Six Livres de la République. Paris 1583, I 1 (Faksimile: Aalen 1961). Der Kirchenvater wendet sich allerdings in seinem Zitat gegen Ciceros Idee einer autopoieti- 
Der Grund für die letztliche Gleichbehandlung von einfachen Wegelagerern und Banditen mit Staatsfeinden dürfte während der Antike in der eingeschränkten Durchsetzungskraft der Behörden gerade außerhalb der Städte gelegen haben. Diese zeigt sich in der Problematik um das im folgenden zu beschreibende Eirenarchat und spiegelt sich in der allgemeinen Einschätzung der durch Banditen hervorgerufenen Übel wieder: Den Tod durch Banditen zu erleiden, galt geradezu als Einfluß höherer Gewalt und wurde in den römischen Gesetzestexten zusammen mit Tod durch Schiffbruch und Naturkatastrophen aufgezählt. Das Banditentum war auf den Straßen und zur See allgegenwärtig, was durch die bekannte Geschichte von Caesars Gefangennahme durch Piraten illustriert wird. " Symmachus, im Jahr 384 Stadtpräfekt von Rom, traute sich im Vorjahr aus Furcht vor einem Überfall nicht einmal ins unmittelbare Umland. ${ }^{12}$

Daraus läßt sich folgern, daß die in schriftlichen Quellen verwandte allgemeine Bezeichnung latro für gewalttätige Opponenten mit der Existenz eines staatlichen Gewaltmonopols steht und fällt, das eine solche Klassifizierung faktisch erst ermöglicht. Das Römische Reich verfügte zwar über ein solches gesetzlich fixiertes Ge-

schen Rechtssetzung qua virtus, wie sie sich in Alexanders Eroberungszug ausdrückte, um dem weltlichen Staat die Rechtssetzung abzusprechen: Ohne einen Bezug zum Göttlichen, so Augustinus, könne es auch keine staatliche Legitimation geben; er formuliert damit die für die Spätantike charakteristische christliche Abkehr vom Ideal des in die Krise geratenen Staatswesens, vgl. Gustave Combes, La doctrine politique de Saint Augustin. Paris 1927, 92, 279. Der neuzeitliche Staatsphilosoph Jean Bodin (1529-1596) versuchte, die Staatsgewalt auf ein von der religiösen Sphäre unabhängiges rechtliches Fundament zu stellen. Durch die Völkerwandenungszeit war die Legitimation der Staatsgewalt in eine Aporie geraten; Augustinus kam in seinem „Gottesstaat" zu einer Neubegründung in der ausschließlich religiösen Sphäre. Vermittelst des mittelalterlichen Gottesgnadentums fand diese Idee gleichsam wieder vom Himmel zurück auf die Erde. Bodin definierte im Gegensatz dazu am Beginn seiner Sechs Bücher über den Staat diesen als eine ,am Recht orientierte Regierung", was eben gerade den Staat von Räuber- und Piratenbanden unterscheide und ihn gleichzeitig vor Tyrannenwillkür bewahre, République est un droit gouvernement de plusieurs mesnages, \& de çe qui leur est commun, avec puissance souveraine: Jean Bodin, Six Livres de la République. Paris 1583, I 1, dt. Übers. mit Anm. Bernd WIMMER, Sechs Bücher über den Staat, Bd. 1, München 1981, 575-578, Anm. 12 14a. Räuber waren somit für Bodin, und hier kehrte er zur antiken Definition zurück, Feinde in einem totalen Sinn, da sie den Untergang der gesamten, auf (von Menschen) gesetztes Recht gegründeten Ordnung anstreben.

11 Vell. II 42; Plut. Caes. 2; Suet. Caes, 4; zuletzt hierzu Luciano CANFora, Caesar, Der demokratische Diktator. München 2001, 24-27.

12 Symm. ep. II 22, ed. u. frz. Übers. Jean Pierre CAllu, Paris 1972: Sed nunc intuta est latrociniis suburbanitas, atque ideo praestat macerari otio civitatis, quam pericula ruris incidere; vgl. SHaw (1984) 6, der ihn schon in diesem Jahr Stadtpräfekt sein läßt; SÜNSKES THOMPSON (1990) 191; PLRE I 865-870 s.n. 'Symmachus 4'. 
waltmonopol: Seit Beginn der Kaiserzeit galt die lex Iulia de vi publica, ${ }^{13}$ die Privatleuten das Waffentragen verbot und gewaltsamen Aufruhr mit dem Tode bestrafte. Doch konnte und wollte das Römische Reich, wie alle vormodernen Staaten, diesen Anspruch niemals völlig durchsetzen. Gerade im juristischen und polizeilichen Bereich war den Städten im Reich die Selbstverwaltung überlassen. Dies erklärt, warum sich der Gedanke eines umfassenden staatlichen Gewaltmonopols im antiken Recht nicht materialisieren konnte. Charakteristisch für die antike Staatsauffassung von Plato bis Augustinus ist vielmehr die organische Metapher vom Staatskörper als einer Gesamtheit, deren einzelne Teile sich von unten her streng solidarisch verhalten. ${ }^{14}$ Eine alles bis ins kleinste Detail regelnde zentrale Obrigkeit war somit im antiken Staatsdenken zunächst gar nicht vorgesehen. In einigen Gegenden des Römischen Reiches waren Gebirge, Wälder und Sümpfe de facto staatsfreie Räume; Rom versuchte, dies auszugleichen, indem in den dortigen Gebieten spezielle Kommandos gegen die Räuber aufgestellt wurden. ${ }^{15}$ Somit waren diese Gebiete wohl im neuzeitlichen Sinne einer zentralen staatlichen Kontrolle entzogen, doch deshalb mitnichten gleich rechtsfrei: Kleinere dörfliche Gemeinden formten ganz im Sinne der antiken Idee der lokalen Autonomie Netzwerke der Ordnungssicherung.

Dieses auf lokaler Selbstverwaltung und dem Fehlen einer eindeutigen Polizeimacht (s.u.) begründete Gleichgewicht war - hinsichtlich der Idee einer funktionstüchtigen Reichsverwaltung - recht labil. Es brach zusammen, als die Einfälle der Germanen und Hunnen zunahmen. An der zeitweisen Aufgabe des Waffenmonopols im 5. Jahrhundert tritt diese Entwicklung am deutlichsten hervor: Nach einem durch Mark Aurel im Markomannenkrieg gegebenen Präzedenzfall, als „Räuber“, in Wahrheit wohl Angehörige halbnomadischer dalmatischer Stämme zu Hilfspolizisten gemacht und mit Waffen ausgestattet werden mußten, konnte es unter Julian und Valentinian I. mit Charietto ein Räuber 365 zum comes per utramque Germaniam bringen. ${ }^{16}$ Später sah sich im Westreich Valentinian III. angesichts der drohenden Invasion Italiens durch die Vandalen dazu genötigt, auch Sklaven bewaffnen zu lassen. ${ }^{17}$ Diese negative Entwicklung wurde generell in der Spätantike durch die

13 Dig. 48, 6, 3, $1 \mathrm{ff}$.

14 Mommsen (1887) III 1 720f. 744. 749f.; Mario BRETONE, Geschichte des römischen Rechts, München 1992, 170; Wolfgang KUnKEL / Martin SCHERKAIER, Römische Rechtsgeschichte, Köln-Weimar-Wien 132001, 48, 180.

15 S.o. Kap. IV.1.4 u. RIESs (2001) 111, Anm. 125.

16 Amm. XXVII 1, 2-6; Zos. III 7; Suda A 2395; PLRE I 200 s.n. 'Charietto 1'; DemandT (1989) 267, Anm. 41.

17 SHA M. Aurelius 21, 7f.: [Marcus] latrones etiam Dalmatiae atque Dardaniae milites fecit; armavit et diogmitas. - Nov. Valentiniana IX (De reddito iure armorum). Vgl. Jan BURIAN, 'Latrones milites facti. Ad SHA Marc. 21, 7', in : Eunomia 2 (1960), 47 ff.; RIEss (2001) 183. 
sogenannte Patroziniumsbewegung verstärkt, als die Bauern sich durch Flucht zu den abgesperrten Gehöften ihrer Landesherren dem Zugriff des Fiskus entzogen. ${ }^{18}$ In diesem Zusammenhang ist der Wechsel in den Konflikten von Banditenaufständen zu regelrechten Kleinkriegen zu sehen: Während der Goten- und Isaurieraufstände im Ostreich schlossen die Armee und sogar einzelne Gemeinden auf eigene Rechnung mit dem Feind separate Friedensverträge, so im Falle von Germanicopolis während des Isaurier-Aufstands von 354 oder von Selge während der Tribigild-Revolte zum Ende des 4. Jahrhunderts. ${ }^{19}$ Aus den Räubern waren nun Feinde auch im engeren Sinne geworden. Diese Entwicklung, die im Zusammenhang mit den Ereignissen der Völkerwanderung zu sehen ist, schuf die Voraussetzung für eine erneute Klassifizierung der in der Hohen Kaiserzeit romanisierten Isaurier als Barbaren.

\subsubsection{Die Maßnahmen der Magistrate gegen das Räuberunwesen}

Ein großer Nachteil beim Umgang des Staates mit den exorbitanten isaurischen Raubzügen stellte der Umstand dar, daß im Römischen Reich, mit Ausnahme Ägyptens, das über eine Jahrtausende alte Verwaltungsgeschichte verfügte, keine effektive und zentral gesteuerte polizeiliche Infrastruktur im neuzeitlichen Sinne existierte, ${ }^{20}$ auch wenn sich eine große Anzahl von gesetzlichen Vorkehrungen gegen das Räuberunwesen findet. ${ }^{21}$ Somit war der Staat für die Durchführung von Polizeiaufgaben entweder auf die Armee oder auf zivile lokale Autoritäten angewiesen.

Für die Verbrechensbekämpfung in den Provinzen war der jeweilige Provinzstatthalter verantwortlich; aufgrund der mandata principis war er zur Verfolgung von latrones, sacrilegii, plagiarii, fures und überhaupt mali homines verpflichtet. Die staatlichen Polizeikräfte standen also ausschließlich im Dienst der Städte. ${ }^{22}$ Sofern diese nicht für eigene Truppen auf ihrem Umland sorgten, gab es keinerlei Polizei auf dem Land, sieht man einmal vom Militär ab, das mit stationes, Patrouillen und Sonderkommandos (wie im Umland von Termessos) auf die Sicherheit der Straßen

18 CTh I 29, 8; vgl. DEMANDT (1989) 329, 333-336; 409; relativierend zur Rolle des Patroziniums bei der Transformation der spätantiken Gesellschaft KRAUSE (1987).

19 Vgl. o. Kap. III. 2.

20 Zu diesem Komplex NipPel (1995) passim, zu den Isauriern ebda. 101f.; Riess (2001) passim; Ägypten: 207-211.

$21 \mathrm{Zu}$ gesetzlichen Vorkehrungen gegen Räuber vgl. die älteren Arbeiten von Otto HIRSCHFELD, 'Die Sicherheitspolizei im römischen Kaiserreich' (1891) in: Ders., Kleine Schriften. Berlin 1913, 591-596 u. MOMMSEN (1899) 306-315, 629f., 660 ff. GS VI (1900) 154.

22 Paul. Dig. 1, 18, 3; Ulp. Dig. 1, 18, 13 pr. ; Marc. Dig. 48, 13, 4, 2; P.Oxy. XII 1408; BGU 646; vgl. GRÜNEWALD (1999) 33f. mit Anm. 61; RIESS (2001) 205 f. 
achtete. $^{23}$ So mußten die Provinzialen bei einer konkreten Bedrohung eigene Milizen aufstellen. In Reaktion auf größere durch Banditen hervorgerufene Schäden verließ man sich in zunehmendem Maße auf erratische Taten wie spektakuläre Hinrichtungsaktionen. Dies traf beispielsweise auf die Hinrichtung der Isaurier in Iconium zu, um die übrigen Banditen, derer man nicht habhaft werden konnte, abzuschrecken. ${ }^{24}$ Polizeiliche Aufgaben wurden ohne übergeordnete Instanz oder Absprache zwischen Statthaltern, Gemeinden und der Armee geteilt, die mit der Durchführung von größeren Polizeiaufgaben betraut wurde. Letztere fungierte damit als eine Art interner Polizeimacht. In den Märtyrerakten finden sich Soldaten in der Funktion von Untersuchungsrichtern, Vollzugsbeamten, Folterknechten und Henkern. ${ }^{25}$ Zwar gab es im Westen eine eigens gegen die Räuber eingerichtete Behörde des praefectus arcendis latronibus, aber es existiert kein Hinweis auf eine integrale behördliche Verbindung zwischen dieser und der römischen Militärmacht, welche dann letztlich die gefährlichen Banditen zu verfolgen hatte. ${ }^{26}$

In den senatorischen Provinzen der Hohen Kaiserzeit waren in der Regel keine Legionen stationiert. Die Statthalter waren deshalb bei der Verfolgung von Banditen zunächst allein auf die zivilen Autoritäten angewiesen. ${ }^{27}$ Die Munizipalaristokratien stellten zu diesem Zweck ein liturgisches Amt zur Verfügung, das Eirenarchat. ${ }^{28}$ Bereits der Name verrät, daß es bei diesem Amt eher auf die Erhaltung des sozialen Friedens als etwa auf die Durchsetzung eines Gesetzeskatalogs im neuzeitlichen

23 Vgl. Hopwood (1989a) 192: „Municipal policing failed to impinge on the non-urbanised interior"; LEWIN (1993); GRÚNEWALD (1999) 34: „Überhaupt kennzeichnet Hilflosigkeit das Verhalten des römischen Staates gegenüber der weit verbreiteten, vor allem in kleinem Stile betriebenen Kriminalität."

24 Amm. XIV 2; vgl. NiPPEL (1995) 103; s.o. Kap. IV. 2.1.1.

25 SHAW (1984) 18 mit Anm. 36.

26 SÜNSKES THOMPSON (1990) 199.

27 ILS 6087 für die Kaiserzeit; vgl. Yann LE BoHEc, L 'Armée Romaine sous le Haut-Empire, Paris 1990, 32f.; Mitchell (1995a) 196.

28 Marc. Dig. 48, 3, 6, 1 ff.: Eirenarchen und die Definition ihrer Befugnisse unter Antoninus Pius: Ergriffene Räuber waren über ihre Genossen und Hehler zu verhören, Dig. 50, 4, 18,

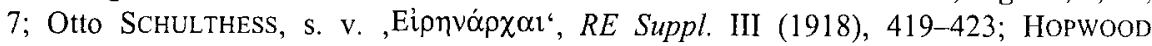
(1983). (1989a) 192f;; RIESs (2001) 48. 205f. Der erste Beleg für Eirenarchen ist eine karische Inschrift aus Kisildjeh (Sebastopolis), auf 116 oder $117 \mathrm{n}$. Chr. datiert: P. PARIS / M. HolleauX, 'Inscriptions de Carie' in: $B C H 9$ (1885), 324-328, 347; vgl. Riess (2001) 205, Anm. 207. Ein weiterer früher Beleg stammt aus Ägypten zur Zeit des Septimius Se-

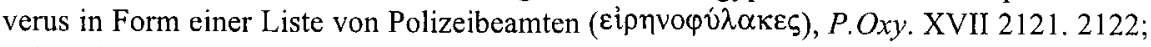
vgl. Heinz BELLEN, Studien zur Sklavenflucht im römischen Kaiserreich, Wiesbaden 1971, 103; SÜNSKES THOMPSON (1990) 202; RIESS (2001) 208 mit weiterer Literatur. 
Sinne ankam. ${ }^{29}$ Die Römer hatten diese Methode, sich ordnungspolitisch auf lokale Autoritäten zu stützen, in den östlichen Provinzen von den hellenistischen Potentaten übernommen. Das Eirenarchen-Amt war wegen der hohen Kosten und Risiken unter den städtischen Notabeln unbeliebt, doch andererseits war es als Liturgie mit öffentlichen Ehrungen verbunden. ${ }^{30}$ Auch in der Spätantike blieben die Eirenarchen in den Provinzen für lokale polizeiliche Aufgaben zuständig. Doch angesichts der Zunahme von größeren räuberischen Aktivitäten stieß dieses System rasch an seine Grenzen, und die Armee wurde wieder zur Bekämpfung der Räuberbanden gerufen: So mußten bereits im 3. Jh. gegen die marodierenden Banditen in der chora von Termessos zur Verstärkung militärische duces den lokalen Autoritäten zu Hilfe kommen. ${ }^{31}$

Die Eirenarchen bedienten sich für besondere Aufgaben der paraphylakes, diese wiederum der bereits in hellenistischer Zeit bezeugten Diogmiten (,Verfolger"), mithin Lokalmilizen als unmittelbarer Exekutivorgane. Diese aus der lokalen Bevölkerung, durchaus auch Sklaven, rekrutierten Rollkommandos wurden auch während der Christenverfolgungen aktiv. ${ }^{32}$ Wegen ihrer Unzuverlässigkeit und Brutalität und aufgrund der daraus resultierenden Gefährdung des inneren Friedens wurden sie nur in extremen Notlagen mit scharfen Waffen ausgestattet. Im 4. Jahrhundert verdammte Basilius von Caesarea in den canones, die er an seinen bischöflichen Kollegen Amphilochius von Iconium richtete, die dortigen Diogmiten, denn sie waren offenbar einer letalen präventiven Gewalt gegen Räuber nicht abgeneigt: Nach Teilnahme an derartigen Aktionen, die sich nördlich des isaurischen Kernlandes abgespielt haben müssen, sollten Laien fürderhin von der Kommunion ausgeschlossen, Kleriker entlassen werden. ${ }^{33}$

29 Zutreffend der Aphorismus von HoPwood (1986) 350 für die Provinzen: „there was order, but no law".

30 Sieben Ehreninschriften publiziert von HoPwOOD (1983) $185 \mathrm{ff}$.

31 ZIMMERMANN (1996) 273; ergänzend IGR III $481=$ ILS 8870 aus der 2. Hälfte des 3 . Jhs., s.o. Kap. IV.1.4.

32 Bibliographie zu den Diogmiten bei Louis RoBERT, Le Martyre de Pionios, prêtre de

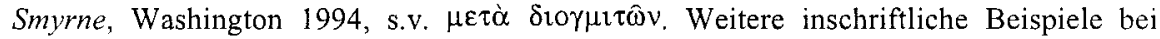
HOPWOOD (1983). (1984). (1989a). Gegen dessen peiorative Deutung der Diogmiten als ausschließlich ,halbprofessioneller Killer" wendet sich RIESS (2001) 207f. Zwei weitere von HOPWOOD (1989a) 193, Verweis auf MAMA III 305 (Korykos) übersehene inschriftliche Zeugnisse für die Diogmiten, BM II Nr. 20 (Çatlıçukur) und IGR III 830 (Syedra) listet LeNSKi (1999b) 310, Anm. 13 u. 321 mit Anm. 58 auf. Mitchell (1995a) 197 deutet die Lokalmilizen als Teil eines Unterdrückungsapparats der hellenisierten bzw. romanisierten Stadtbewohner auf die indigen gebliebene Landbevölkerung. Diese These kann jedoch nicht einmal für die frühe Kaiserzeit eine Geltung für ganz Kleinasien beanspruchen.

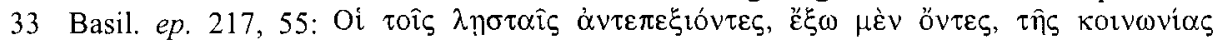

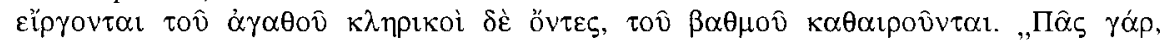

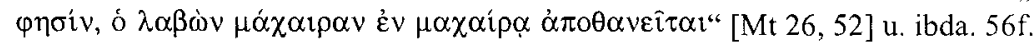


Auch die Eirenarchen kamen den ethischen Verpflichtungen ihres Amtes, mit Augenmaß für Ordnung zu sorgen, nicht mehr nach. Wohl vor allem ihre offenbar unrühmliche Rolle bei den ausgedehnten Isaurierunruhen um die Wende vom 4. zum 5. Jahrhundert führte zum Verbot der gesamten Berufsgruppe im Jahr 409. Im entsprechenden Gesetz werden sie gar als ,gemeingefährlich“ bezeichnet. ${ }^{34}$ Sie scheinen nicht nur wegen fortwährender Überforderung ineffizient, sondern auch, selbst an spätantiken Verhältnissen gemessen, in hohem Maße korrupt gewesen zu sein. Kurioserweise war das Amt im nachfolgenden Gesetzeswerk, dem Codex Iustinianus unter der gleichen Überschrift im Jahr 409 offenbar wieder erlaubt, denn hier wurde angeordnet, daß die Curialen im Einvernehmen mit den Provinzstatthaltern geeignete Eirenarchen ernennen sollen. ${ }^{35}$ Der in der Spätantike stattfindende Zentralisierungsprozeß zuungunsten der kommunalen Selbstverwaltung zeigt sich hier darin, daß die Ernennung eines Eirenarchen der Genehmigung durch den Statthalter bedurfte. Auch die Erwähnung eines weiteren, aus dem Jahr 420 stammenden Gesetzes, wenngleich dieses nicht unproblematisch ist, ${ }^{36}$ legt den Schluß nahe, daß die Eirenarchen unter Theodosius II. zunächst abgeschafft und dann doch wieder eingeführt wurden $^{37}$ - offenbar, weil man die Erfahrung gemacht hatte, daß die Armee mit Polizeiaufgaben erst recht überfordert war.

Zumindest für Isaurien kann jedoch angenommen werden, daß es bei der Abschaffung des Eirenarchenamtes blieb und statt dessen für die zivile Verwaltung eigene sogenannte Klimatarchen unter der direkten kaiserlichen Oberhoheit geschaffen wurden, die damit von den kommunalen Strukturen völlig unabhängig waren. Die Möglichkeit einer solchen Maßnahme legt der Name der vier isaurischen „Klimata“ westlich jener äußerst schroffen und bergigen Gegend nahe, des oberen Kalykadnoslaufs, in welchen das Zentrum der isaurischen Unruheherde vermutet wird. Hier

34 CTh XII 14, 1: genus perniciosum rei publicae; vgl. HOPWOOD (1983) 181. (1986) 352. (1999a) 192; RIESs (2001) 182. 207.

35 CJ X 77: Irenarchae, qui ad provinciarum tutelam quietis ac pacis per singula territoria faciunt stare concordiam, a decurionibus iudicio praesidum provinciarum idonei nominentur. - Die Erklärungsversuche von HopwOOD (1999a) 192. 200, Anm. 94 bleiben unbefriedigend: „It is, of course, possible that the edict suppressing eirenarchs took the definition from an earlier, now lost, text, which was then assimilated into the definitions sections with its new date still attached."

36 CJ X 1, 9: super irenarcho et optione omni antiqua consuetudine observanda. Vgl. DEMANDT (1989) 407 u. 199 Anm. 22. Die Erwähnung der Eirenarchen in diesem Text ist insofern problematisch, als es darin in erster Linie um die Militärmagazinverwalter geht und darum, daß den Milizen weiterhin Futter und Verpflegung zur Verfügung gestellt werden solle. Die Observanz militärischer Dinge unterlag jedoch niemals einem Eirenarchen. Zudem steht der Text auch am falschen Ort, da sich der Titel X eigentlich mit dem Fiskalrecht befaßt; vgl. OTto/ SchILLING $C J$ (1832) 412, Anm. 13.

37 Anders RIESs (2001) 182. 
verband sich eine hohe Siedlungsdichte mit geographischer Unzugänglichkeit. ${ }^{38}$ Auch der unter Justinian dienende Beamte Johannes Lydus verweist auf eine Existenz der Klimatarchen lange vor Justinian, denn er beklagt in seiner aus der Sicht eines zentralistisch orientierten und kaisertreuen Beamten verfaßten Suada gegen den praefectus praetorio Orientis Johannes, daß die Klimatarchen durch diesen verhaßten „Kappadokier“ ihrer Aufsichtsfunktion beraubt wurden, indem er den Klimatarchen die Aufsicht über die Steuerlisten entzogen und sie seinem eigenen officium zugeschanzt habe. ${ }^{39}$ Allerdings lassen sich weitere $\kappa \lambda \hat{i} \mu \alpha \tau \alpha$ (,Regionen“) als Verwaltungseinheiten, die auch eines Klimatarchen bedurften, erst in byzantinischer Zeit und nur für das Thema Chersonnes nachweisen. ${ }^{40}$ Gerade in Isaurien versuchte der Staat also nach einschlägigen Erfahrungen mit der Ineffizienz der lokalen Ordnungshüter die Ordnung aufrecht zu erhalten und mit der Einführung des comes Isauriae nicht nur die militärische, sondern mit den Klimatarchen auch die polizeiliche Kontrolle an sich zu binden.

\subsection{Ursachen und Art des isaurischen Banditentums}

War das isaurische Banditentum in der dortigen Gesellschaftsstruktur fest verwurzelt? Bildete es ein archaisches Grundmuster und somit von vornherein eine Alternative zum griechisch-römischen Modell des Zusammenlebens? Wie kam es im einzelnen schließlich zu den weiträumigen Raubzügen der Isaurier? Diese Fragestellungen leiden zugegebenermaßen unter der schmalen Quellenbasis, so daß man aufgrund der (mit Ausnahme des Candidus-Fragments) ausschließlich von den Gegnern der Isaurier verfaßten Literatur auf mehr oder weniger plausible Spekulation angewiesen ist. ${ }^{41}$

Fest steht, daß das isaurische Banditentum durch die große zeitliche und räumliche Ausdehnung der Konflikte als außergewöhnlich im Vergleich zu anderen Bewegungen wie den zeitgleich mit den großen Isaurieraufständen agierenden Circum-

38 Not. episc. I 854-857; s.o. Kap. III.2.4.; HeLlENKEMPER (1986) 630 nimmt diese Klimata selbst als Zentrum der Unruhen an; s.o. IV.2.1.4.

39 Joh. Lyd. de mag. III 68; vgl. PLRE III 1 s.n. 'Fl. Ioannes 11' 627-635; CARNEY (1971) 183; TOMASCHITZ (1998) 79f.

40 Vgl. dazu Const. Porph. De adm. imp. 42, 8, 72; Alexander Kazhdan, s.v. 'Klima', $O D B$ 2 (1991) 1133; G. MAKRIS, s.v. 'Chersonnesos 3', DNP 2 (1997) 1118.

41 Vgl. die Skepsis von TOMASCHITZ (1998) 35f.: „Überhaupt sind die sozialen und wirtschaftlichen Hintergründe für das isaurische „Räuberwesen“, wie es in der antiken und in der modernen Literatur gerne bezeichnet wird, ebenso wie die Auswirkungen auf die urbane Bevölkerung der betroffenen Landstriche nicht gut genug bekannt, um eindeutige Zusammenhänge herstellen zu können.“ 
cellionen oder Maratokuprenen anzusehen ist. ${ }^{42}$ Einzig die Bagauden-Aufstände in Gallien (280-435) können hinsichtlich der (unterstellten) Neigung zum Separatismus und der Wandlung von ehemals römischen Bürgern über Rebellen zu latrones mit jenen der Isaurier verglichen werden. Die Bagauden, deren Namen wohl aus der keltischen Wurzel bag- für „Kampf“ gebildet ist, ${ }^{43}$ rekrutierten sich vermutlich aus einfachen Reichsbürgern, die dann, gleich den Isauriern, als Reichsfeinde angesehen wurden. ${ }^{44}$ Doch auch bei diesem Beispiel ist die Quellenlage zu dürftig, um einen Separatismus oder einen Plan anzunehmen. Überhaupt ist schwer auszumachen, in welcher Weise sich bei den Bagauden soziale und antirömische Motive zueinander verhielten. ${ }^{45}$ Eines läßt sich jedoch mit Sicherheit feststellen: Parallel zu jenen der Isaurier erfolgten ihre Aufstände in Wechselwirkung mit den Barbareneinfällen, und auch gegen die Bagauden wurden gotische Föderatentruppen eingesetzt.

Einen anderen Erklärungsansatz für das in Isaurien auftretende Banditentum verfolgt Keith HoPwOOD in mehreren Arbeiten. Er vermutet einen aus dem speziellen landschaftlichen Profil erwachsenen Charakter der sozialen Bindungen. Banditen und herrschende Klasse seien in Isaurien miteinander verwoben gewesen. Dies habe sich dann im römischen System der städtischen Selbstverwaltung durch die Curialen fortgesetzt. Da Landbesitz eine Voraussetzung der Zugehörigkeit zur Curialenklasse war, dürften viele Bauern von den Curialen abhängig gewesen sein, deren Ländereien sie bewirtschafteten. ${ }^{46}$ Die Curialen rekrutierten aus diesen Bauern und Hirten ihre eigenen Polizeikräfte. So wurden die marodierenden Goten unter Tribigild auch von einem pisidischen Landbesitzer namens Valentinian mit Hilfe seiner Bauern und Hirten vertrieben, die dieser zuvor wohl als seine eigenen lokalen Ordnungseinheiten

42 Vgl. Riess (2001) 52. Circumcellionen: DEMANDT (1989) 463f.; Maratokuprenen (Amm. XXVIII 2, 11-14): Santos Yanguas (1977); Demandt (1989) 312, Anm. 41. ARCE (1973) vergleicht die Isaurierkämpfe des 3./4. Jahrhunderts mit den gleichzeitigen in Nordspanien. Sie hätten eine soziale Unzufriedenheit ausgedrückt.

43 Anders Clifford E. MNOR, 'Bacaudae: A Reconsideration' in: Traditio 51 (1996), 297307.

44 Salvian de gubernatione dei, ed.f. PAULY (CSEL 8), Wien 1883, V 24: ius Romanae libertatis amiserant, etiam honorem Romani nominis perdiderunt.

45 Samuel SZÁDECZDY-KARDoss, s.v. 'Bagaudae', RE Suppl. XI (1968), 346-354 mit abgemildert marxistischer Deutung; DemandT (1989) 49f., 309f.; Johnf. Drinkwater, 'The Bagaudae of fifth-century Gaul' in: Ders. / Hugh ELTON, Fifth-century Gaul. A crisis of identity?, Cambridge 1992, 208-217; Juan Carlos SÁNCHEZ LÉON, Les sources de l'histoire des Bagaudes: traduction et commentaire, Paris 1996 u. die Einträge in CAH XIV (2000). Gegen die bisherige Forschung argumentiert Clifford E. MNOR, 'Reclassifying the Bacaudae, Some Reasons for Caution, Part I: Who Were the Third Century Bacaudae?' in: Ancient World 28 (1997), S. 167-183; Part II, in: Ancient World 30 (1999), 29-43.

46 Zuletzt HOPWOOd (1999a) 184-187; SHAW (1990) 241 vermutet ein ,traditional arrangement" zwischen den Berg- und Talbewohnern. 
benutzt hatte, um die Ordnung auf seinen Ländereien aufrecht $\mathrm{zu}$ erhalten. ${ }^{47}$ Die isaurischen und pisidischen Städte weiteten womöglich auf diese Weise ihre Einflußmöglichkeiten durch die Patronage über Transhumanz betreibende, also nicht zur Einwohnerschaft dieser Städte gehörende Hirten aus. Somit haben sich diese vom Land stammenden bewaffneten Aufsichtsleute über die Hirten und Bauern, welche die Interessen der städtischen Curialenklasse wahrnahmen, aus derselben sozialen Quelle wie die Banditen gebildet. ${ }^{48}$ Mit dieser Annahme erklärt Hopwood auch das rapide Anwachsen der bei Ammian geschilderten Aufstände: je nach politischer Großwetterlage wurden die lokalen Polizisten plötzlich zu Banditen.

Es stellt sich dennoch die Frage, ob dieses System nicht weniger gegen das Imperium Romanum gerichtet als vielmehr auf Dauer kompatibel mit der Art der römischen Herrschaftsausübung war: So sind die Einwohner von Germanicopolis sicherlich in die isaurischen Aktivitäten involviert gewesen, womöglich sogar als Grundherren einiger isaurischer Banditen, und hatten aufgrund dieser Stellung Zugang zu beiden Gruppen, was sie als Vermittler prädestinierte. ${ }^{49}$ Lokale Potentaten waren unter diesem Aspekt eher Machthaber im letztlich staatstragenden Sinne als Banditen. Somit sind nach HOPwOOD die Konflikte zwischen den Isauriern und der römischen Ordnungsmacht eher als eine Serie von „Disputen“ über Natur und Ausdehnung römischer Macht anzusehen als mit einem starren Banditenkonzept zu erklären, wie SHAw dies tat. ${ }^{50}$ Diese These vom Banditentum als festem, graduell auch von den lokalen Eliten getragenen Bestandteil der regionalen Gesellschaftsordnung ist nicht ganz von der Hand zu weisen, ${ }^{51}$ erklärt jedoch immer noch nicht das hohe Ausmaß und die lange zeitliche Dauer der isaurischen Raubzüge. So ist hier vor

47 Zos. V 15; s.o. IV.2.4.

48 HOPWOOD (1999a) 188.

49 Amm. XXVII 9, 7, s.o. Kap. IV.2.1.1. Hopwood (1999a) 195 stellt die Einwohner von Germanicopolis als ,power-brokers" dar, im Anschluß an R. ADAMS, 'Brokers and career mobility systems in the structure of complex societies' in: Southwestern Journal of Anthropology 26 (1970) 315-327, 320: „His actual control over either sphere depends upon his success in dealing with the other; his controls in one level of articulation provide a basis for controls in another ... he controls one domain only by virtue of having access to derivative power from a larger domain." Gegen den Wortlaut der Quelle geht HOPWOOD (1999a) 179 jedoch von einer Gleichrangigkeit der Verhandlungen aus: ,[...] giving the hint that there may have been, at least initially, a mutual exchange of hostages“. Doch dann hätten auch von römischer Seite aus Geiseln gestellt werden müssen, wovon im Text keine Rede ist.

50 Hopwoon (1999a) 189, 197: „If banditry was the crisis faced by the Roman state, it faced a series of locally provided governments."

51 Vgl. Thomas Grunewald, Rez. Hopwood (1999a) in: GfA 2 (1999) 1087-1091. 1088; http://www.gfa.d-r.de/2-99/gruenewald.pdf. 
allem die Frage zu stellen, wie diese Konflikte motiviert waren: ökonomisch, politisch oder ethnisch? Im Folgenden soll dafür eine Erklärung versucht werden.

\subsubsection{Kontinuität eines lokalen Tribalismus?}

Der Widerstand gegen die römische Eroberung in den beiden Jahrhunderten vor und nach Christi Geburt ist auf Grundlage der Quellen nicht weiter in Frage zu stellen: Die Stämme in dieser Region widersetzten sich dem Ausgreifen der römischen Macht und der damit einhergehenden Ausbeutung des provinzialen Raumes während der Zeit der Republik. ${ }^{52}$ Eine völlig andere Lage ist nach vollzogener Romanisierung in der Spätantike gegeben. Gleichwohl kommt Brent SHAW zu einer anderen Ansicht: In Auseinandersetzung mit den Thesen von Eric HowBSBAwM, der den Typus der "social bandits" als bäuerliche Gesetzlose in einer Bauerngesellschaft definierte und der Frage nachging, ob es sich hier um eine rein literarische Robin-Hood-Typologie oder echte Figuren des sozialen Protestes handelte, ${ }^{53}$ gibt SHAW zu bedenken, daß der „rein imaginäre" Charakter der von HOBSBAwM behandelten Mythen zu berücksichtigen sei. Die räuberischen Aktionen der Antike seien weniger als sozialer denn vielmehr als ethnischer Protest zu klassifizieren. ${ }^{54}$ Da dieser ethnische Protest seine Wurzeln in vorstaatlichen Gesellschaftsformen habe, müsse er letztendlich von vornherein als rein ethnisch-politisch bezeichnet werden. Der Bandit in archaischen Gesellschaften sei zunächst den übrigen gesellschaftlichen Gruppen ebenbürtig gewesen. Bei Homer habe es noch keine soziale Stigmatisierung des Banditen gegenüber dem ehrbaren Helden gegeben. ${ }^{55}$ Doch dabei unterschlägt SHAw den adligen Kontext der Epen, die Logik von Verschwendung und Raub, der nur den oberen Klassen vorbehalten war. Denn es lassen sich auch Stellen anführen, die eine Verurteilung des Räuberwesens nahelegen, am bekanntesten dürfte die Verdammung der Freier am Hof des Odysseus sein. Zudem beziehen sich die von SHAw angeführten

52 Hierzu s.o. III.1.

53 HOBSBAWM ( $\left.{ }^{2} 1972\right)$.

54 ShaW (1984) 51; Sünskes ThOMPSON (1990) 193. Auch Burian (1984) 19 weist die Deutung des latrocinium als klassenkämpferisch motivierte Aktionen zurïck; der Begriff wurde vielmehr allgemein für Gesetzesbrecher verwendet, welche die römische Herrschaft nicht akzeptierten. Doch seine Interpretation von Dig. 49, daß auch Staatsfeinde als latrones bezeichnet worden seien, ist insofern irrig, als in diesem Gesetz die latrones gerade ausdrücklich von den Staatsfeinden, den hostes, unterschieden werden, s.o. IV.3.1.1.

55 SHAW (1984) 23 ff. unter Verweis auf die bei Hom. Il. IX 138=280; XI 677; XII 7; XVIII 327 vorkommende $\lambda \dot{\eta} \iota \varsigma$. 
Beispiele ausschließlich auf die trojanische Kriegsbeute. ${ }^{56}$ Die Annahme eines allgemeinen Einverständnisses einer antiken Gesellschaft mit dem Banditenwesen läßt sich aus keiner Quellen herleiten. Antike Staaten, so SHAw weiter, hätten aufgrund ihrer begrenzten Möglichkeit der Herrschaftsausübung in den von ihnen beherrschten Gebieten Raum lassen müssen für eine Gruppierung, deren Status in Opposition zum Staat zu definieren sei; im Gegensatz zu gewöhnlichen Kriminellen sei diese Gruppierung eben als Gesetzlose und Banditen bezeichnet worden. Dies treffe auch und gerade für die Isaurier zu. Die isaurische Räuberei repräsentiere somit eine „fossile“, gleichsam in die griechisch-römische Zivilisation hineinwirkende, vorstaatliche Kontinuität von ungezähmten Gewaltmenschen. Die in den Quellen immer wieder vorkommenden Schilderungen von Riesenhaftigkeit, Schnelligkeit und Gefährlichkeit einzelner Banditenchefs, wie bei dem Isaurier Indacus, der zur Zeit von Kaiser Leo die Strecke von seinem Bergkastell Papirion nach Antiochia (wohl jenes am Cragus) ${ }^{57}$ und von dort nach Neapolis in der isaurischen Dekapolis an jeweils nur einem Tag gelaufen sein soll, ${ }^{58}$ seien somit nicht nur ein literarischer Topos, sondern eine auf vorkulturelle Gesellschaften rekurrierende Chiffre für die Legitimation der Führungsqualitäten dieser Stärksten. Und diese wiederum die Wirklichkeit konstituierende literarische Topik (wie auch zuweilen das Leben die Kunst imitiert) habe infolgedessen selbst die „Eliten" gegen jegliche Form der Akkulturation immunisiert. ${ }^{59}$ Die römischen Autoren und Autoritäten, so Shaw, hätten die Isaurier gleichsam miß-

56 Des weiteren führt SHAw (1984) 26f. Aristot. Pol. 1256a-b an. Dieser zählt die Räuberei (zunächst ohne Wertung!) neben Ackerbau, Viehzucht, Fischen und Jagd zu den Arten des Broterwerbs, woraus SHAw eine Gleichwertigkeit des Räuberwesens noch in der klassischen griechischen Zeit konstruiert. Erst danach, mit dem Wachsen des Römischen Reiches, sei eine gesellschaftliche Abwertung des Räuberwesens erfolgt. So habe die Etymologie latro aus der Wurzel ${ }^{*} L A T R$ eine Bedeutungsverschlechterung von dem

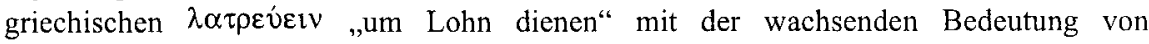
Söldnerarmeen zu latro erfahren. Der Söldner galt jedoch schon immer als sozial niedrigstehend, und die Übernahme eines zuvor neutralen Begriffs für eine gesellschaftlich verachtete Tätigkeit zu Zeiten, als dieses Phänomen zuerst auftauchte (in unserem Beispiel die Landplage der marodierenden Söldner vor dem Niedergang des Hellenismus), beweist nicht, daß der Raub auch nicht schon zu früheren Zeiten eine gesellschaftlich verachtete Praxis war, die einfach nur mit einem anderen, den Sachverhalt drastischer ausdriickenden Begriff belegt wurde.

57 BLOCKLEY (1983) 482, Anm. 6.

58 Suda I 368, X 200; BM II 147; PLRE II 590f., s.n. 'Indacus Cottunes'. Bei $50 \mathrm{~km}$ Luftlinie wären dies $80-100 \mathrm{~km}$ auf Pfaden über steile Steigungen gewesen. Nimmt man nicht das syrische, sondern das isaurische Antiochia (ILS 740 mit TIB 5,1 193 s.v. 'Antiochia') als Ziel an, welches in der Nähe von Neapolis in der isaurischen Dekapolis gelegen ist, so ist die Distanz u.U. auch für Normalsterbliche zu schaffen.

59 SHAW (1990) 261. 
verstanden, indem sie die diese als Banditen diffamiert und nicht als gleichwertige Kombattanten ernst genommen hätten. ${ }^{60}$

Gegen einen solchen über die Zeit der römischen Ersteroberung oder „Befriedung" der Taurusregion in der Republik und der frühen römischen Kaiserzeit hinausgehenden politischen, durch die Aufrechterhaltung der eigenen soziokulturellen Werte motivierten Widerstand jedoch spricht vor allem der Umstand, daß es, nach der erratischen Natur der Aufstände zu schließen, keine über einzelne Aktionen hinausgehende Organisation dieser Aufstände gab. Der Fall von Cremna, den Stephen MiTCHELL für eine solche Annahme als Beweis anführt, ${ }^{61}$ stellt gerade die unerhörte Extremsituation dar.

Somit ist eine Erklärung des fortgesetzten isaurischen Banditentums allein aus einer ethnischen oder auch nur tribalen Andersartigkeit der Isaurier, d.h. einer wie auch immer gearteten kulturellen Differenz zum griechisch-römischen Kulturkreis, angesichts der vorhergehenden Hellenisierung und Romanisierung der Isaurier ausgesprochen problematisch. ${ }^{62}$ Angesichts der grundlegenden Veränderungen im Sozialgefüge Kleinasiens über die Jahrhunderte ist von vornherein einem prozessualen Modell, das auch die Akkulturationsprozesse berücksichtigt, gegenüber einem rein statischen der Vorzug zu geben. In der Spätantike sind hinsichtlich des Wiederaufflammens der isaurischen Raubzüge die Schwächen in der römischen Verwaltungspraxis und die Einfälle der Goten gewichtigere Faktoren. Gleichwohl legt der vielfach bezeugte Stolz der Isaurier auf ihre Herkunft einen Fortbestand des Zugehörigkeitsgefühls zum eigenen Stamm nahe. Gerade zum Ende des 5. Jahrhunderts begann dies eine Rolle in den Auseinandersetzungen zwischen mächtigen Goten und Isauriern am konstantinopolitanischen Hof zu spielen. ${ }^{63}$

60 So auch Linda HONEY in einem im April 2003 an der University of California, Los Angeles gehaltenen Graduiertenvortrag, 'Justifiably Outraged or Simply Outrageous? The Isaurian Incident of Ammianus Marcellinus XIV 2, 1', Abstract in http://www.bol. ucla.edu/ sjm1/lateantiquity/honey.html, 21.07.2003. Sie unterstellt SHAw (1990) allerdings auch, dass er eine rein ökonomische Ursache der Isaurieraufstände annehme.

61 MiChell (1995c) passim.

62 Wohl in Anlehnung an das British Empire formulierte RaMSAY (1941) 4: „The chief opponent of Imperial unity was [...] tribal feeling. This was a unity contrary to the imperial system."

63 Anders ElTon (2000a), der eine Rolle der Ethnizität für die Zugehörigkeit zur Macht negiert; s.u. V.2.2. 


\subsubsection{Streben nach Autonomie?}

Aufgrund der oben beschriebenen Abhängigkeit von der Stärke des betreffenden Staatswesens bei der Definition von Staatsgegnern als schlichte Banditen oder ebenbürtige Feinde stellt sich die Frage, inwieweit die Isaurier nun als Opponenten zum Römischen Reich auch von uns eher in ersterem oder letzterem Sinne angesehen werden sollen, mithin ob sich im Terminus „Banditen“ lediglich die abwertende Fremdbezeichnung durch unsere fast ausschließlich römischen - und damit romfreundlichen - Quellen widerspiegelt (die einzige Ausnahme stellt der isaurische Historiker Candidus dar). ${ }^{64}$

Die Idee einer Quasi-Autonomie Isauriens durchzieht seit der ersten den Isauriern gewidmeten Arbeit die Forschung und kann als eine Fortführung der oben diskutierten topischen Stadt-Land-Dichotomie angesehen werden. ${ }^{65}$ Sie hat ihren Ursprung wohl in der o.g. Fehlinterpretation einer Stelle aus der Historia Augusta über die angenommene Existenz eines inner-isaurischen Limes. ${ }^{66}$ Zuweilen wird Germanicopolis wegen der von Ammian geschilderten Vermittlertätigkeit gar als Hauptstadt eines autonomen Isauriergebiets vermutet. ${ }^{67}$ Vor allem die Arbeiten von Brent D. SHAW haben diese Ansicht befördert. ${ }^{68}$ In der Cambridge Ancient History heißt es, traditionelles Banditentum habe in der Spätantike ganze Regionen unpassierbar gemacht, als Beispiel hierfür ist Isaurien angeführt. ${ }^{69}$ Wenn eine archaische, auf körperlicher Gewalt beruhende Form der persönlichen Machtausübung sich mit bergiger Topographie verbände, konstatiert SHAw, bildeten sich autonome „BanditenGebiete" innerhalb des Römischen Reiches, die zugleich ethnische Rückzugsgebiete und potentielle Schutzräume vor staatlicher Verfolgung darstellten. In diesem Sinne hätten sich auch die Isaurier niemals beherrschen lassen, weder von den Hethitern, noch von den hellenistischen Königen, noch von den Osmanen. Die Isaurier seien

$64 \mathrm{Zu}$ Candidus zuletzt ROBERTo (2001).

65 Zuerst vertreten durch BROOKS (1896) 201, zitiert bei HopwOod (1986) 344: „The Isaurians had maintained their independence against the Romans [...] their independence had been so far recognised that they were designated as barbarians and seem never to have obtained the Roman citizenship“; zuletzt bei Benjamin ISAAC in: CAH 13 (1998) 452f,, 460; „The Isaurians achieved a semi-independent status in their own region“; komplette Aufzählung der Forschungsmeinungen s.o. I.1.1.

66 S.o. IV.2.3.

67 Santos Yanguas (1977) $372 \mathrm{zu}$ Amm. XXVII 9, 7: „La paz con ellos, reconociendo de esta forma [...] la existencia de un estado libre isáurico en el interior del Imperio, estado cuya principal ciudad parece ser, según la decripción ammianea, Germanicopolis."

68 SHaw (1984); ältere Arbeiten zum Thema ebda. 3, Anm. 3. 42. (1990) 261: „foreign enclave within the Roman state".

69 MARCONE CAH XIII (1998) 368. 
damit weniger ganz gewöhnliche Banditen, wie sie von Ammian, Zosimus und anderen dargestellt werden, sondern hätten vielmehr eine vollkommen autonome Opposition zum Imperium Romanum gebildet. Als nun im politischen Chaos des 3. Jahrhunderts die Aufstände der Isaurier zunahmen, seien die traditionellen, auf der vorstaatlichen Gewalt basierenden Herrschaftsstrukturen wieder zum Vorschein gekommen; überhaupt seien sie zu allen Zeiten stärker als die römische Autorität geblieben. ${ }^{70}$

Auch Werner RIESS übernimmt diese These und definiert die Isaurier in einer Typologisierung der antiken Räuber ${ }^{71}$ denn auch nicht als „,randständige Räuber“ im klassischen Sinne, die mit der Wahl ihres Lebensstils als Entwurzelte außer dem Leben nichts mehr zu verlieren hatten, sondern als „vollkommen integrierte Mitglieder einer kriegerischen Hirtengesellschaft, die mit den Ordnungsvorstellungen der fremden Mächte an der Küste in Konflikt geraten waren. ${ }^{72}$ Wie SHAw klassifiziert er die isaurischen Räuber als eine ,nonkonforme Kontrakultur ${ }^{\text {“ }}{ }^{73}$ Sie seien von Rom schlicht als Räuber „gelabelt" worden.

Doch wie sich im bisherigen Verlauf der Arbeit gezeigt hat und im weiteren zu zeigen sein wird, gibt es zwar zahlreiche Hinweise in den Quellen auf einen Zusammenhang zwischen dem Niedergang der staatlichen Ordnung und den im 3. Jahrhundert beginnenden zahlreichen Raubzügen, und für ein verstärktes ethnisches Selbstbewußtsein bei den Isauriern ab dem 5 . Jahrhundert. ${ }^{74}$ Doch es gibt keinen einzigen Beleg für ein Streben nach Abspaltung vom Reich oder für eine kulturelle Abkapselung im Sinne von Nonkonformität. Gerade die in den nächsten Kapiteln dargestellten Karrieren isaurischer Mächtiger zeigen deren Bestreben, sich rasch in die römische Elite und in deren System einzubinden, nicht, es zu unterwandern. Dies läßt sich bis hin zu jenem Longinus beobachten, der nach dem Tod seines kaiserlichen Bruders Zeno die Macht in isaurischen Händen zu halten versuchte. Damit ist es als fraglich anzusehen, ob das isaurische Banditentum mit SHAw als eine Form von „politischer Anachoresis“ vom römischen System der Herrschaftsausübung bezeichnet werden kann. Zudem lassen Hinweise aus einem Nachbargebiet noch längst keine Rückschlüsse auf Prozesse in dem topographisch anders gegliederten Isaurien zu, und wie oben bereits dargelegt, müssen angesichts des hohen Romanisierungs- und Urba-

70 Zur Widerlegung dieser These angesichts des hohen Romanisierungsgrades s. auch o. Kap. II. 2 .

71 RiEss (2001) 89-94

72 RiESS (2001) 52f. mit Anm. 53; ZIMMERMANN (1996); s.o. Kap. IV.1.4.

73 RIESS (2001) 157.

74 Zum Ergebnis, daß das erneute Auftreten isaurischer Gewalt seit dem 3. Jahrhundert eher politische als geographische oder soziologische Ursachen hatte, gelangt auch LENSKI (1999a) 446. Zum ethnischen Selbstbewußtsein contra ElTON (2000a) s.u. V.2.2. 
nisierungsgrades in Isaurien große Zweifel bestehen, ob es sich bei den Bewohnern Isauriens überhaupt noch um eine reine „,kriegerische Hirtengesellschaft" gehandelt hat. $^{75}$

Dabei braucht keineswegs der Umstand ausgeschlossen zu werden, daß in Krisenzeiten Truppen von gewaltbereiten Briganten vorübergehend durchaus ungestört agieren konnten. Das eingangs erwähnte Abenteuer des Banditen Palfuerius im 3. Jh., der mit Cremna in Pisidien eine ganze Stadt zur Geisel nahm, war im Endstadium kein kleiner Aufstand mehr. Das Ausmaß dieses bewaffneten Konflikts zeigen die gigantischen Belagerungswerke, welche die Legionäre vor den Stadtmauern aufgetürmt hatten. Palfuerius hatte mit seinem Aufstand offensichtlich die Schwelle vom latro zum hostis überschritten, doch blieb dieses Ereignis ein Einzelfall ohne Folgen für die Stabilität der römischen Herrschaft. Die Belagerung Cremnas erfolgte gegen den Willen der ansässigen Bevölkerung. ${ }^{76}$ Auch die als Emanation einer gewissen Organisation des isaurischen Widerstands interpretierte Geschichte um den fiktiven Usurpator Trebellianus aus der Historia Augusta ist wohl eher im allgemeinen Tenor der Schrift zu verstehen, „schlechte“ Soldatenkaiser „,guten“ senatsfreundlichen Kaisern kontrastiv gegenüberzustellen. Zwar kontrollierten im 4. Jahrhundert isaurische Banditen über einen längeren Zeitraum römische Festungen an Straßenkreuzungen, aber diese Fälle blieben episodisch und reichen für die Annahme eines langfristigen Strebens der Isaurier nach Eigenstaatlichkeit nicht aus.

Gerade Ammians erster Satz bei der Schilderung der Raubzüge von 368 zeigt, $\mathrm{da} ß$ auch die isaurischen Städte und Villen selbst nicht vor Plünderungen sicher waren. Ammian gibt auch keinerlei Hinweis auf isaurische Abspaltungsbestrebungen. Er beklagt vielmehr die Zunahme des Räuberunwesens als Folge einer durch korrupte Beamte hervorgerufenen Verelendung der Provinzen. Somit ist bei Ammian die durch die isaurischen Räuber hervorgerufene Plage auch eine Folge der verfehlten Politik von Kaiser Constantius II. und Valens, zu deren Regierungszeit sich die bei ihm geschilderten Aufstände zugetragen haben. ${ }^{77}$ Die isaurischen Banditen, die gegen die Soldaten und Behörden kämpften, traten nicht als geschlossene Volksgruppe auf. Von dem Krieg des Anastasius gegen die Isaurier abgesehen gibt es keinen Fall, in dem eine isaurische Stadt sich gegen Rom erhoben hat. Die Trennungslinie zwischen „Römern" und „Barbaren“ (im Sinne von „Reichsfeinden“), wie die Isaurier in den Quellen genannt werden, verlief somit wohl eher innerhalb der isaurischen Bevölkerung. Diese Spannung zwischen Romanisierung und Revolte widerspricht nun dem

75 LENSKI (1999a) 417, 447f. gegen die in verschiedenen Arbeiten geäußerten Ansichten von HOPWOOD; s.o. Kap. III.2.4.

76 Hierzu s.o. Kap. IV.1.3.

77 Demandt (1965) 55, 59. 
statischen Bild, das SHAW mit seiner Behauptung von einer durch alle Epochen gleichbleibenden isaurischen Autonomie entwirft. ${ }^{78}$

Aus dieser Frage ergibt sich eine weitere, die sich aus den Quellen jedoch nicht beantworten läßt: Gab es ein Zentrum des isaurischen Widerstands gegen Rom, und wenn ja, wo war es gelegen, im ländlichen oder im städtischen Raum? Die letztere Annahme kann eine gewisse Plausibilität beanspruchen, wenn man davon ausgeht, daß es sich um ökonomisch motivierte Aufstände handelt. Spekulativ bleibt damit die Antwort auf die Frage, ob es Sympathisanten innerhalb der Städte gab. Zumindest die in den Miracula überlieferte Geschichte über die isaurische Geisel Bassiane und das weitere Schicksal ihres Sohnes als angesehener Bürger in Eirenopolis deutet auf eine solche Verflechtung zwischen städtischer Oberschicht und Landbevölkerung hin. ${ }^{79}$

Gleichwohl rekrutierten sich die Räuber selbst offenbar nicht aus den Polisbürgern, sondern, wie bereits oben dargelegt, aus von den Bergen herabkommenden Weidebauern. Inwieweit diese organisiert waren, muß nach den einzelnen Aufständen differenziert betrachtet werden: Die von Ammian geschilderten Unruhen machen trotz ihres großen Umfanges, der die Dimensionen von einfachen Hirtenaufständen weit gesprengt hat, ${ }^{80}$ nicht den Eindruck, als ob hier ein längeres Ziel verfolgt wurde, während die Raubzüge durch den östlichen Mittelmeerraum diesen Schluß schon eher zulassen.

Beachtung verdient die Tatsache, daß bei den antiken Autoren die Isaurier oftmals nicht insgesamt als Banditen oder Barbaren bezeichnet werden; zwischen den Banditen und der übrigen isaurischen Bevölkerung muß also differenziert werden. ${ }^{8 !}$ Der Autor der Vita und der Miracula vermeidet überhaupt die Bezeichnung „Isaurier"; er nennt sie lediglich „gefährliche Nachbarn", „Plagegeister" oder schlicht „Räuber“. Der Grund dürfte darin liegen, daß er eine Differenzierung zwischen den von den Bergen herabkommenden Isauriern und jenen romanisierten in der Ebene vornehmen will. ${ }^{82}$ Die Städte gelten in dieser Quelle gleichsam als Inseln der Zivilisation in einem Ozean der Barbarei.

78 Vgl. Mitchell (1995a) 77, Anm. 74: „The important general study by B. D. Shaw ... neglects to consider the specific ways in which the Highlands were controlled under the Romans".

79 Mir. 28.

80 LENSKI (1999a) gegen HOPWOOD (1989b).

81 So Amm. XXVII 9, 6 At in Isauria globatim per vicina digressi praedones oppida villasque uberes libera populatione vexantes magnitudine iacturarum Pamphyliam afflictabant et Cilicas; SHA Prob. 16, 5 barbarorum qui apud Isauros sunt kann nur die Sympathisanten in der Bevölkerung meinen, welche die Banditen unterstützen, vgl. PASCHOUD SHA (2001) 125 .

82 So DAGRON Mir. (1978) 114. 
Zutreffender dürfte angesichts der oben geschilderten anzunehmenden Verbindungen zwischen Stadt und Land jedoch die Vermutung sein, daß die isaurischen Banditen sich zumindest teilweise aus dem verarmten städtischen Proletariat rekrutiert haben könnten. ${ }^{83}$ Isaurien kann somit nicht als ein homogener Staat von Banditen bezeichnet werden. ${ }^{84}$

\subsection{3 Ökonomische Motivation der Raubzüge}

Aus dem bisher Gesagten ergibt sich, daß sich die großen isaurischen Raubzüge noch am ehesten als wirtschaftlich, nicht originär politisch motiviert beschreiben lassen. ${ }^{85}$ Die Bauern verließen ihre Scholle, verbündeten sich mit den Hirten und flohen mit ihnen in die Berge. ${ }^{86}$ Dieses Muster blieb seit $51 \mathrm{n}$. Chr. in dem von Tacitus geschilderten Aufstand der Kietai, der sich gegen eine Steuererhebung richtete, ${ }^{87}$ gültig. Die landwirtschaftliche Grundlage reichte nach den zahlreichen kriegsbedingten Verwüstungen im 3. und 4. Jahrhundert nicht mehr aus, um die Bevölkerung zu ernähren. ${ }^{88}$ War eine solche kritische landwirtschaftliche und politische Großwetterlage nicht gegeben, so ist in den Quellen auch nichts von isaurischen Raubzügen zu vernehmen. ${ }^{89}$ Somit erscheint ein Kausalzusammenhang mit den bezeugten äußeren Einflüssen am plausibelsten. Eine neue Qualität erreichten die isaurischen Raubzüge erst, als die Banditen aufgrund des gesteigerten militärischen Drucks gleichsam die Flucht nach vorn antraten und in die Nachbarprovinzen einfielen.

Freilich hatten die isaurischen Attacken auch eine negative Rückwirkung auf die ökonomische Situation in der eigenen Region, welche die politische und soziale Krise

83 Marcone CAH XIII (1998) 369.

84 Hierzu vgl. LENSKI (1999b) 320, allerdings im leichten Widerspruch zu (1999a) 430, dort vermutet er Quasi-Autonomie zu Beginn des 5. Jahrhunderts: „its leaders had become powerful enough to dictate not just regional affairs but to extend their influence to the capital.“

85 So zuletzt auch Elton (2000a) 296.

86 Vgl. HopwoOd (1999a) 180

87 Tac. ann. VI 41; s.o. III.1.2.

88 SANTOS Yanguas (1977) 353; Isaurien hatte einen Überschuß an Bevölkerung ,to recruit into banditry“: HoPwOOD (1989a) 196; zu Engpässen in der Nahrungsmittelversorgung als Ursache für Brigantentum vgl. auch SÜNSKES THOMPSON (1990) 195.

89 So kommt Santos Yanguas (1977) 353, 355, 372 auf der Suche nach einer Motivation des isaurischen Banditentums nach der Diskussion dreier ,herkömmlicher“ Erklärungsansätze (politischer Separatismus, Klassenkampf - hierzu DEMANDT (1984) 274 ff., 572 ff. und „supervivencia simple de tribalismo local“ zur Lösung, sie als „sachkundige Räuber" zu bezeichnen: in guten Zeiten sei es ihnen gelungen, mit den Römern in Frieden zu leben, in schlechten sei es ihnen gelungen, sich alles Lebensnotwendige zu holen. 
nur noch verstärkte, denn sie unterbrachen die Handelsrouten..$^{90}$ Damit war der Wirtschaftskreislauf gestört, was einen Teufelskreis der Verarmung in der Region zur Folge haben mußte. Vor allem bei jenem von Ammian geschilderten Aufstand des Jahres 354 spielt der Kampf um Nahrungsmittel eine große Rolle, wie die Plünderung des Getreidespeichers in Palae verdeutlicht. ${ }^{91}$ Weiterhin schildert Ammian, wie es den isaurischen Briganten bei der Belagerung eines römischen Heeres in Seleucia gelang, Versorgungsschiffe zu kapern und so ihre Verpflegung sicherzustellen. ${ }^{92}$ Es ist anzunehmen, daß sich die Poleis im isaurischen Binnenland vom Meer aus über den Kalykadnos mit Getreide versorgten. Während der Unruhen mußte also die Versorgung dieser Städte unterbleiben.

In der Ammian-Stelle über den Aufstand von 368 ist beschrieben, wie die römischen Truppen die Briganten in ihren Bergnestern regelrecht aushungerten. Es gab zu dieser Zeit also weder ertragreiche Ernten noch Vorratshaltung in Isaurien. Mithin dürfte eine zunehmende Nahrungsmittelknappheit infolge der allgemeinen Krise im 3. Jahrhundert auch für die sprunghaft ansteigende Häufigkeit der isaurischen Aufstände nach 260 verantwortlich gewesen sein, als die Handelswege unsicher geworden waren. Die knapp 120 Jahre später, im Jahr 386, erlassene Steuererleichterung für die ostanatolischen Provinzen, nach welcher der Satz der capitatio, der Pro-Kopf-Steuer, dort auf zwei bis drei Männer oder vier Frauen gerechnet wurde, läßt auf wirtschaftliche Schwierigkeiten in der Region schließen, auch wenn Isaurien nicht mit genannt ist. $^{93}$

\subsubsection{Administratives Versagen}

Die hohe Zahl der isaurischen Aufstände im 4. Jahrhundert läßt sich weiterhin durch die mangelnde Organisation der römischen Provinzialverwaltung erklären. Vor allem in der Diözese Oriens häuften sich die Vorkommnisse; sie stehen im Zusammenhang mit dem Schreckensregiment des Caesars Gallus in Antiocheia. Der Isaurier-Aufstand von 354 fand in unmittelbarer zeitlicher Nachbarschaft mit der Hungerrevolte in Antiocheia von 353 statt, in deren Verlauf der städtische Pöbel vom Caesar selbst zur Lynchjustiz an den eigenen Magistraten aufgerufen wurde - die öffentliche Ordnung war auf diese Weise nicht nur von außen und unten, sondern auch von oben gefährdet. ${ }^{94}$ Weiterhin ereignete sich ein Judenaufstand; Sarazenen und einheimische Mara-

90 Ballance (1958).

91 Amm. XIV 2, 13, weitere Literatur s.o. IV.2.1.1.

92 Amm. XIV 3, 19.

93 CJ XI 48, 10; vgl. DEMANDT (1989) 247.

94 Amm. XIV 1; 7, 6; 9; 11; Lib. or. I 103; DEMANDT (1989) $84 \mathrm{f}$. 
tokuprenen plünderten Syrien. ${ }^{95}$ In Antiochia gab es unter Theodosius 387 Unruhen im Theater und Straßenkämpfe, gegen welche die Behörden lange nichts unternahmen. ${ }^{96}$ Auch auf die Gainaskrise konnte der geschwächte Staat lange nicht adäquat reagieren. Die marodierenden Truppen des aufständischen Goten schufen ein Klima der Unsicherheit und Angst; viele Gemeinden machten die Erfahrung, daß sie sich nur selbst helfen konnten.

Gegenüber den gleichzeitigen isaurischen Aufständen zeigte die Regierung keine Angemessenheit in ihrer Reaktion auf die vielfältigen Krawalle und die Kriminalität. Nicht selten kam es zu Überreaktionen der parteiischen Justiz, was entsprechende Reaktionen provozierte. ${ }^{97}$ Die andauernde Ohnmacht der römischen Verwaltung gegen die isaurischen Räuberbanden ist somit nicht zuletzt aus der Unfähigkeit zu erklären, eine angemessene Reaktion auf die ökonomischen und militärischen Krisen dieser Zeit zu finden. ${ }^{98}$

Das deutlichste Beispiel für eine derartige staatliche Überreaktion auf Banditentum ist die Verurteilung isaurischer Banditen im Amphitheater von Iconium ad bestias, die einen der größten Aufstände des 4. Jahrhunderts zur Folge hatte. Ammian geißelt diese Maßnahme als sittenwidrig (praeter morem) ${ }^{99}$ Die gefangenen Isaurier wurden als Räuber, nicht als Kriegsgefangene behandelt. Sie waren somit, wie oben dargelegt, rechtlos. ${ }^{100}$ Ein Edikt Hadrians erlaubt zwar ausdrücklich die Verurteilung von gefaßten Straßenräubern ad bestias, wenn sie sich Mordtaten schuldig gemacht

95 Aur. Vict. 42, 11; Hieron. chron. s.a. 352; Socr. h.e. II 33; Amm. XXVIII 2, 11-14 mit SANTOS YANGUAS (1977).

96 Lib. or. XIX 34-37; Downey (1961) 426-435; TINNEFELD (1977) 154-163; NiPPEL (1995) 110.

97 Vgl. HopWOOD (1989a) 196; NiPPEL (1995) 112; Riess (2001) 52.

98 MACMULLEN (1966) 262f. (1988) 182 findet eine Erklärung für den Umstand, warum die Isaurier trotz ihrer relativ geringen Zahl eine unkontrollierbare Kraft im Osten im 4. Jh. werden konnten, indem er die Kritik Ammians übernimmt, wonach die Magistrate damit beschäftigt gewesen seien, die Provinzialen auszuplündern; der Feind suchte mittlerweile die Landstriche heim, ohne nennenswerte Gegenwehr der mittlerweile "verweichlichten" Soldaten: Amm. XV 13, 4 (Persien); XXVII 9, 6. Auch das syrische Inland benötigte trotz der Vernichtung der isaurischen Banditen im Jahr 408 Stadtbesatzungen gegen andere Räuber bis in die Tage des Symeon Stylites, der 459 starb. Das Banditentum der Isaurier sei also nur ein Reaktion auf die korrupte römische Verwaltungspraxis und somit „der Preis für die Privatisierung der Regierungsgeschäfte" gewesen.

99 Amm. XIV 2, 1. HOPWOOD (1999a) nimmt, nachdem er keine Gesetzesgrundlage gefunden hat, als Grundlage des ammianischen mos die Art und Weise, die „moral economy“ der Verhandlungen zwischen Banditen und Ratsangehörigen an. Dies dürfte eine seiner Theorie folgende Überinterpretation sein. Ammian geht es lediglich um die guten altrömischen Tugenden, die er in seinem Werk vielfach einklagt. An mehreren Stellen macht er deutlich, daß er die Strafen als zu hart und grausam empfindet.

100 SEYFARTH Amm. (1968) 257, Anm. 25 zu Amm. XIV 2, 1. 
haben, ${ }^{101}$ doch Ammian nennt die Exekutierten consortes der Aufständischen. Man kann also davon ausgehen, daß diese sich nichts zuschulden haben kommen lassen, zumindest kein Kapitalverbrechen, und wohl einfach stellvertretend für jene hingerichtet wurden, derer man nicht habhaft werden konnte. Ammian will wohl diesen Umstand mit seiner Formulierung, die Verurteilung sei praeter morem gewesen, ausdrücken.

Mit der zunehmenden Schwächung des Gewaltmonopols erodierte auch die Rechtssicherheit; der Staat verlor aus Hilflosigkeit allmählich seine Legitimation, bei gleichzeitigem Bestehen auf Normdurchsetzung. Dies befeuerte möglicherweise erst recht den Widerstand der Banditen. ${ }^{102}$ Im Jahr 391 wurde schließlich der Selbstjustiz Tür und Tor geöffnet, als die Tötung mutmaßlicher Banditen durch Privatpersonen als präventive Verteidigung von Theodosius genehmigt wurde. ${ }^{103}$ Möglicherweise ist auch der erste in den erhaltenen Büchern Ammians geschilderte Aufstand von 354 von unfähigen oder überforderten Curialen provoziert worden, die ihre Befugnisse überschritten bzw. ihre Machtfülle mißbrauchten. ${ }^{104}$

Der Verlauf sämtlicher von den Quellen geschilderter Aufstände läßt sich folgendermaßen schematisieren: Zunächst überfielen isaurische Banditen die umliegenden Siedlungen und Städte. Sie rekrutierten sich vermutlich zum Großteil aus Hirten und Bauern, denen die wirtschaftliche Grundlage entzogen war. Darauf antwortete die römische Ordnungsmacht, oftmals spät, militärisch. Die zivilpolizeiliche Ausstattung der Poleis war, wie oben dargelegt, nicht auf diese Art der Bedrohung angelegt. Damit wuchsen sich die Aufstände gelegentlich zu regelrechten Kriegen aus, der Konflikt bekam auf diese Weise eine gewisse Eigendynamik. Gegebenenfalls wurden die bäuerlichen Banditen durch verarmte Tagelöhnern aus den Städten verstärkt. Mit der militärischen Vertreibung der Banditen in das Hochland endete der Konflikt bis zur nächsten Auseinandersetzung.

Mit der zunehmenden Befestigung der Städte und der stärkeren Kontrolle der Straßen waren die isaurischen Banditen nun gezwungen, in Nachbarräume auszuweichen. ${ }^{105}$ So lassen sich die Plünderungen in Cypern, Palästina und Rhodos noch im folgenden 5. Jahrhundert erklären. Dabei tragen diese schon aufgrund ihrer Stoßrich-

101 Dig. 48, 19, 28, $15 \mathrm{f}$.

102 RIESS (2001) 93; zur Diskussion um den spätantiken „Zwangsstaat“ vgl. DEMANDT (1997).

103 CTh IX 14, 2 = CJ III 27, 1; RIESS (2001) 193.

$104 \mathrm{Vgl}$. HOPWOOD (1999a) $192 \mathrm{f}$.

$105 \mathrm{Vgl}$. Amm. XIV 2, 8: metuentes igitur idem latrones Lycaoniam magna parte campestrem, cum se impares nostris fore congressione stataria documentis frequentibus scirent. 
tung eher den Charakter von Raubzügen als daß sie sich gemäß der von SHAW und RIESS vertretenen Deutung als separatistisch motivierte Aktionen bezeichnen ließen.

In den über die gesamte Epoche des Kontakts mit dem Römischen Reich verteilten isaurischen Aufständen lassen sich drei Typen unterscheiden:

- Widerstand gegen Eroberung / Besteuerung im 1. Jh. (tribale Phase),

- ökonomisch motivierte Raubzüge im 3. und 4. Jahrhundert in Reaktion auf die Bedrohung des Reichs von außen v.a. durch die Goten sowie eine inadäquate Verwaltung,

- ethnischer Konflikt nach der Verdrängung aus der bereits erreichten Macht unter Anastasius.

Als ein wesentlicher, neu hinzukommender Faktor für die Aufstände in der Folgezeit ist das sich während der Wende vom vierten zum fünften Jahrhundert rapide verstärkende Gotenproblem zu betrachten. Dazu kam der mißratene Feldzug Julians, der den Osten destabilisierte, und die 15 Jahre später erfolgte Katastrophe von Adrianopel. Die Wirtschaft im Osten lag in der zweiten Hälfte des 4. Jahrhunderts vor allem deshalb darnieder, weil die Bedrohungen des Reichs durch Goten und Perser zusammenkamen, und sollte sich erst wieder unter Theodosius II. vorübergehend erholen, unter dessen Regierungszeit sich die byzantinische Diplomatie ausbildete. ${ }^{106}$ So ist es auch kein Zufall, daß wir in den ersten Jahrzehnten des Theodosius II. von keinen isaurischen Aufständen mehr hören. Noch zur Zeit der pilgernden Nonne Egeria waren die Isaurier eine konstante Bedrohung der zivilisierten Poliswelt gewesen. Auch die Probleme, die der Kaiser Zeno mit den Goten und den Usurpationen hatte, sind eng mit der Gotenproblematik verknüpft. ${ }^{107}$

\subsubsection{Piratentum?}

Eine wiederholt diskutierte Teilfrage ist jene nach einem eventuellen Piratentum der Isaurier: Ob sie sich an der Piraterie der Kilikier zur republikanischen Zeit beteiligt haben und ob sich die bezeugten Aktionen zur See in der Spätantike als Piratentum bezeichnen lassen. Die Panegyriker des Anastasius, jenes Kaisers, der die Isaurier nach ihrer Vorherrschaft unter Kaiser Zeno in einem achtjährigen Krieg besiegen konnte, setzen sie mit den kilikischen Piraten gleich und stilisieren Anastastasius zum Nachfolger des Pompeius - im kollektiven Bewußtsein waren Solymer, Kilikier und

106 Demandt (1989) 166-169, 352; Allen D. LeE CAH XIV (2000) 39-42; Bryan WardPERKINS ebda. $381 \mathrm{ff}$. mit der (gegen FINLEY gerichteten) Theorie einer Vernetzung der spätantiken Wirtschaft über den gesamten Mittelmeerraum.

107 S.u. Kap. V.2.2. 
Isaurier eins. ${ }^{108}$ Hier stellt sich allerdings die Frage nach dem historischen Wahrheitsgehalt. In jedem Falle trifft dies auf die in den Quellen dokumentierte Küstenpiraterie zu: Bereits die den Isauriern benachbarten und verwandten Kieten im 1. Jahrhundert n. Chr. störten die Handelsschiffahrt auf diese Weise. ${ }^{109}$ Im 4. Jahrhundert schildert Ammian die Überfälle isaurischer Banditen auf die Küstenschiffahrt, aus der die antike Handelsschiffahrt in der Regel bestand. ${ }^{10}$

Ein anderes Problem ist die großräumige Piraterie. Die Grenzen zwischen Seekrieg und Seeräuberei sind dabei allgemein schwer zu ziehen; in ihrem eigenen Selbstverständnis hatten die sogenannten kilikischen Piraten in der Zeit zwischen den Mithradatischen Kriegen und ihrer Besiegung durch Pompeius wohl den Status von schlichten Räuberbanden hinter sich gelassen und die Form eines militärisch strukturierten, staatsähnlichen Verbandes angenommen. ${ }^{111}$ Allerdings ist die Frage nach der genauen ethnischen Zusammensetzung dieser Piraten nicht genau beantwortet. Höchstwahrscheinlich haben sich auch Isaurier beteiligt. ${ }^{112}$ Diese „kilikischen“ Piraten stammten vermutlich nicht nur aus Kilikien selbst bzw. aus dem bergigen Hinterland, sondern setzten sich auch aus Griechen und Levantinern zusammen. ${ }^{113}$ Die felsigen Buchten des rauhen Kilikien wurden nach Appians Zeugnis als Ankerplatz benutzt, daß die Piraten jedoch aus dieser Gegend gestammt haben sollen, schreibt er nicht, was für eine andere Herkunft der Piraten spricht. ${ }^{114}$ Isaurien selbst war als zusammenhängendes Gebilde jedenfalls nicht mit Mithradates verbündet, sondern wurde sogar ein Eroberungsobjekt des pontischen Königs: dessen Feldherr Eumachos unterwarf es vorübergehend. ${ }^{115}$ Darüber hinaus stellt sich die Frage, ob die Rolle der Piraten in den römischen Kriegen im Osten von der Forschung nicht insgesamt über-

108 S.u. Kap. V.4.2.

109 Tac. ann. XII 55: Nec multo post agrestium Cilicum nationes, quibus Clitarum cognomentum, saepe et alias commotae, tunc Troxobore duce montis asperos castris cepere atque inde decursu in litora aut urbes vim cultoribus et oppidanis ac plerumque in mercatores et navicularios audebant.

110 Amm. XIV 2, 5.

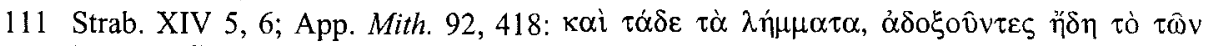

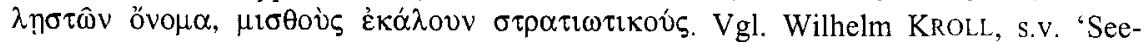
raub', RE II A 1 (1921) 1036-1042, v.a. 1036. 1040; PoHL (1993) 166.

112 S.o. Kap. III.1.2.

113 So RAUH (1997) 268: „Rather they emerged from a vast international substratum of displaced naval warriors from maritime regions under stress." Vgl. auch RAMSAY (1941) 230; POHL (1993) 165 zur unterschiedlichen ethnischen Herkunft der Piraten u. A. Avidov, 'Were the Cilicians a Nation of Pirates?' in: MHR 12 (1997), 5-55; ScHulz (2000) 434.

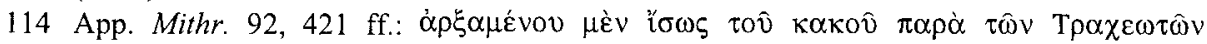
Ki $\lambda i k \omega v$.

115 App. Mithr. 75, 326; SYME (1985) 135; s.o. Kap. III.1.3. 
bewertet wird, denn bis auf wenige Ausnahmen waren die Aktionen der Piraten nicht im strategischen Sinne kriegsentscheidend. ${ }^{116}$

Die Isaurier haben sich aufgrund ihrer Wohnsitze im Landesinneren zu dieser Zeit wohl mehr auf Hehlerei als auf Piraterie beschränkt: zur Zeit der Kampagne des Publius Servilius Vatia bildeten sie den Absatzmarkt für die von den Küstenpiraten erbeuteten Güter. ${ }^{117}$ Daß sie sich bandenmäßig als Küstenpiraten betätigten, wird erst aus den späteren Quellen des 4. und 5. Jahrhunderts deutlich: Ammian schildert, wie isaurische Banditen die Küstenschiffahrt derart terrorisierten, daß diese auf die gegenüberliegende zypriotische Küste ausweichen mußte. ${ }^{118}$ Auf der anderen Seite waren sie nicht in der Lage oder daran interessiert, ihre Opfer zur See zu verfolgen oder einmal gekaperte Schiffe selbst einzusetzen. ${ }^{119}$ Dies spricht gegen eine piratische Aktivität im großen Stil. Auch für die zeitlich folgenden überseeischen Unternehmungen läßt sich ein Piratentum in diesem Sinne nicht ableiten: Als sie gegen Ende des 4. Jahrhunderts sich über See nach Cypern einschifften, oder im 5. Jahrhundert, als sie Rhodos plünderten, ${ }^{120}$ handelte es sich ganz offensichtlich nur um Überfahrten auf Inseln, die dann heimgesucht wurden. Diese Raubzüge lassen sich als eine Reaktion auf die erfolgreichen Befestigungsmaßnahmen der Römer in der zweiten Jahrhunderthälfte deuten: Durch die gestiegene Militärpräsenz im isaurischen Kernland waren die Isaurier gezwungen, auf andere Gebiete auszuweichen. Konstantinopel hatte seine militärischen Probleme mit den Isauriern zu dieser Zeit weitgehend gelöst, doch die ökonomischen Verhältnisse in der Provinz verleiteten diese offenbar zu weiteren Raubfahrten.

116 Nach DE SouzA (1999) 219. 131; vgl. Ders., 'Romans and Pirates in a Late Hellenistic Oracle from Pamphylia' in: $C Q 47$ (1997) 477-481 war die Rolle der Piraten in den Kriegen der Römer in den Quellen überbewertet. Paradebeispiel sei ihre Rolle während des Mithradatischen Krieges: Ihre häufige Nennung spiegelt die Propaganda zwischen Rom und Mithradates wider, die beide versuchten, durch das Versprechen eines Kampfes gegen die Piraterie die Eliten des östlichen Mittelmeers für sich zu gewinnen. Auch die in zahlreichen Inschriften des 3. Jahrhunderts erwähnten Aktivitäten gegen Piraten seien nichts besonderes und kein Krisenphänomen, sondern lediglich ,run-of-the-millactivities" gewesen.

117 Sall. hist. frg. II 86: Pocula et alias res aureas, diis sacrata instrumenta, convivio mercantur; vgl. Maurenbrecher Sall. (1891) 94; MCGushin Sall. (1992) 231; s.o. Kap. III.1.3.

118 Amm. XIV 2, 3.

119 Amm. XIV 2, 9f.; vgl. Marasco (1983) 219

120 Philostorg. h.e. XI 8 (Cypern im 4. Jh.); Joh. Ant. frg. 206, 1 (Rhodos im 5. Jh.); hierzu zuletzt Woods (1998) 116. Nach der mißverständlichen Formulierung von STEIN (1928) 363 fanden die isaurischen Raubzüge in dieser Zeit ,vor allem zur See“ statt. 
Ein Gesetz des Anastasius von 492, welches Seeleute aus Kilikien gegenüber anderen begünstigte, ${ }^{121}$ wurde lange als eine Kompensationsleistung für isaurische Piraterie in Folge des Krieges gegen die Isaurier gedeutet. ${ }^{122}$ Doch bezog sich die den kilikischen Seehändlern zugestandene Zollbefreiung ausschließlich auf Wein; ihre Schiffe waren für eine Übernahme durch Piraten wohl zu klein, und wenn sie andere Lebensmittel wie Getreide oder Trockenfleisch transportierten, fielen sie nicht unter diese Befreiung. ${ }^{123}$

Wohl verdingten sich eine Reihe von Isauriern während der Mithradatischen Kriege als Piraten, und die Bewohner des Hinterlands betätigten sich auch als Hehler für gestohlene Güter und gingen insofern in den ,kilikischen“" Piraten, welche Pompeius zu bekämpfen hatte, mit auf. Im 4. Jahrhundert betrieben sie zwar vereinzelt Küstenpiraterie, folgten den ausweichenden Seeleuten jedoch nicht an die gegenüberliegende cypriotische Küste. Cypern selbst und Rhodos wurden an der Wende zum 5. Jahrhundert in Raubzügen zu Land heimgesucht; analog zum Vordringen bis nach Palästina ist dies als Ausweichmanöver auf gestiegenen militärischen Druck zu interpretieren. Von einer planmäßigen und langfristigen Betätigung der Isaurier als Piraten im engeren Sinne kann also nicht ausgegangen werden.

\subsection{Die Wandlung der Isaurier von Bürgern zu Barbaren}

Nach den Mithridatischen Kriegen galten die Kilikier als sprichwörtliche (See-) Räuber. Diese Bezeichnung aus der Zeit der römischen Republik soll dann nahtlos auf die Isaurier in der Spätantike übergegangen sein, so SHAw. Doch daß sie ein derartiges Synonym für Diebstahl und Raub noch in der Mitte des 2. Jahrhunderts, also während der Ruhe in der Hohen Kaiserzeit dargestellt haben sollten, wie es HopwoOD und SHAw unter Berufung auf den Icaromenippus des Lukian von Samosata behaupten, ist anzuzweifeln. Zwar heißt es dort in der Tat beim Überflug des Ikaromenipp über die Völker des Reiches: „Der Kilikier räubert.“124

Jedoch wirft ein Schluß von diesem Stereotyp auf die Behauptung, die Kilikier (und somit auch die zu dieser Zeit zugehörigen Isaurier) seien selbst während der Periode des größten inneren Friedens in der römischen Geschichte noch räuberisch tätig gewesen, Datierungsfragen der Quelle selbst auf - abgesehen von der methodisch fragwürdigen Vorgehensweise, eine Dichtung ohne weiters als Beleg für tat-

121 OGIS 521. Neue Ed., frz. Übers. und Kommentar bei DurLiat / GuILlou (1984).

122 TIB 5,1 41; anders Durliat / Guillou (1984); vgl. LensKi (1999a) 429, Anm. 80.

123 So Durliat / Guillou (1984) 596.

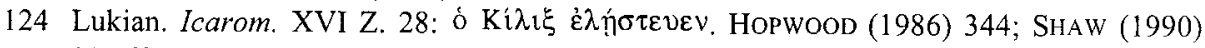
$231 \mathrm{ff}$. 
sächliche zeitgenössische historische Ereignisse anzuführen: ${ }^{125}$ Die literarische Vorlage Lukians, die Werke des Menippos von Gadara, ist vier Jahrhunderte älter als das Erscheinungsdatum des Gedichts und reflektiert somit zunächst die Zustände ihrer eigenen Zeit. Eine räuberische Tätigkeit der Kilikier oder Isaurier während der Hohen Kaiserzeit läßt sich schon deshalb aus dieser Quelle nicht ableiten. ${ }^{126}$

Ganz im Gegenteil existiert eine Schrift aus eben jener Zeit, in welcher die Isaurier selbst in einem positiven Kontext genannt werden: Der gleichzeitig mit Lukian in der zweiten Hälfte des 2. Jahrhunderts n. Chr. wirkende Tatian, wie Lukian syrischer Abstammung, führt in seiner viel gelesenen ${ }^{127}$ „Rede an die Griechen“ die Isaurier als eines jener Völker an, die vor den hier geschmähten Griechen kulturelle Leistungen wie die Schau des Vogelflugs erbracht hätten, wogegen die Griechen ihre gesamte Kultur von anderen Völkern übernommen hätten ${ }^{128}$ - ein Vorwurf, den man allerdings nahezu jedem Kulturvolk machen kann.

Die Ersetzung von „Kilikier" durch „Isaurier“ als Synekdoche für „Räuber“ im literarischen Diskurs muß u. E. mit der Schaffung einer eigenen Provinz Isauria unter Diocletian, spätestens im Verlauf des 4. Jahrhunderts mit den großen Aufständen erfolgt sein. Es gab also nicht, wie es SHAw nahelegt, den Typus des kilikischen Räubers, der dann irgendwann in der Spätantike nahtlos zum räuberischen Isaurier wurde. Vielmehr läßt sich das Schweigen der Quellen so interpretieren, daß in der Hohen Kaiserzeit tatsächlich jene Ruhe des Rechts herrschte, die der Panegyriker Aelius Aristides so überschwenglich gepriesen hat. ${ }^{129}$

125 Auch nach LENSKI (1999a) 431 ist die Stelle nicht mehr als ein bloßer Stereotyp. Zum Verhältnis zwischen Dichtung und Historiographie in der Antike vgl. RIESS (2001) 349374.

126 Dazu schon Helm (1906) 88-114; v.a. 88; 94 ff.: gerade dieser Stereotyp des ,räuberischen Kilikiers" stammt bereits aus der hellenistischen Zeit. Lukian hat lediglich die Meinung des Menippos von Gadara, eines Kynikers aus dem 3, vorchristlichen Jahrhundert, übernommen und ausgeschrieben, offensichtlich ohne zusätzlich eigene Lesefrüchte zu verwenden, denn keine der Darstellungen in der Doxographie der philosophischen Lehrmeinungen oder die literarischen und historischen Anspielungen weisen weit über das 3. Jahrhundert hinaus. Eins der vielen Beispiele ist, daß Zeus sich in XXIV erkundigt, ob die Athener das Olympieion nicht endlich einmal zu vollenden gedächten. Es war in der Tat seit Peisistratos bis zu Hadrians Zeit unvollendet, doch als Lukian den Ikaromenipp verfaßte, war der Zeustempel schon seit mindestens 30 Jahren fertiggebaut. Auch der im 3. Jh. zerstörte Koloß von Rhodos wird in XII noch als bestehend erwähnt. Vgl. auch Heinz-Günther NESSElRath, s.v. 'Lukian von Samosata', DNP 7 (1999), 493-501; Manuel BaUmBaCH, s.v. 'Menippos aus Gadara', ebda. $1243 \mathrm{f}$.

127 Euseb h.e. IV 29, 7.

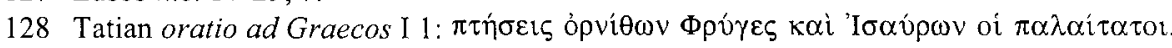

129 Ael. Aristid. Eic 'Pó $\mu \eta v$. 
Bezüglich des 4. Jahrhunderts dagegen ist der Terror, den die isaurischen Banditen während ihrer großen Raubzüge auf die gesamte Gegend ausübten, nicht zu überschätzen. Dies einfach als kulturelle Eigenständigkeit darzustellen, die Isaurier ausschließlich in der Opferperspektive wahrzunehmen und ihre Bezeichnung römischerseits als Repräsentanten der barbarischen Irrationalität auf einen schlichten Widerstand gegen die römische Herrschaft anzusehen, ist ein geradezu eindimensionaler Ansatz. ${ }^{130}$ So ist es nicht verwunderlich, daß auf römischer Seite nach den weiträumigen Aufständen jene Barbarentopik, die vorrangig auf die Germanen zielte, auch für die Isaurier wieder Geltung erlangte: Ihre barbarische, trieb- und damit tierhafte Steuerung führe die Isaurier immer wieder zu ihren Aufständen, schreibt Ammian. ${ }^{131}$ Sein zu Beginn des Aufstandes von 368 gezeichnetes Bild der Banditen, die im Frühjahr Schlangen gleich aus ihren Löchern hervorkriechen, ${ }^{132}$ ist in der Vita des Konon in einer Geschichte über zwei isaurische Wegelagerer wiederholt, die mit Schlangen und Dämonen verglichen werden. ${ }^{133}$ Mit den menschenfressenden Lästrygonen werden sie in den Miracula der Heiligen Thekla gleichgesetzt. ${ }^{134}$ Diese Geschichte ist gleichzeitig ein plastischer Beweis für die Permanenz heidnischer Mythologie in spätantiken Heiligenviten. Der Tiervergleich rückt sie in den Bereich des Barbarischen. ${ }^{135}$ Aus einfachen Banditen und Piraten wurden also Feinde Roms. ${ }^{136}$

130 So teilt SALMON (1997) 78 nicht die Auffassung auch der kirchengeschichtlichen Quellen vom Ende des 5. Jahrhunderts, daß die Isaurier zu Barbaren und Reichsfeinden geworden sind und sieht die Isaurier vorrangig als Opfer des römischen Imperialismus an, vgl. ebda. 82: „Rome veut réaliser la fusion ethnique et l'assimilation juridique des peuples conquis au peuple conquérant. En 212, l'Edit de Caracalla accorde le droit de cité à tous les peuples libres de l'Empire à l'exception des dediticii. Les populations d'Asie Mineure participent désormais à la plénitude de la romanité. La vision négative des Romains se focalise dès lors sur ses ethnies qui tentent de secouer la domination romaine. C'est pourquoi les Isauriens continuent à être considérés au début du ve siècle de notre ère comme des représentants spécifiques de l'irrationalité barbare."

131 Amm. XIV 2, 2 in Berufung auf Cic. Cluent. 67. Schon bei Florus begegnet der Vergleich mit der tierischen Triebhaftigkeit, in welcher die Piraten zu ihrem Gewerbe trotz aller militärischen Niederlagen zurückkehren, Flor. epit. I 41, 6: ut quaedam animalia; vgl. DAUGE (1981) 19f.; SALMON (1997) 68f., 81.

132 Amm. XIX 13, 1: ut solent verno tempore foveis exsilire serpentes, saltibus degressi scrupulosis et inviis. Weitere menschliche Schlangen bei Amm.: XIV 7, 13; XXX I 16f.; XV 2, 4. 7, 4; vgl. BARNES (1998) 108 .

133 V. Cononis 12 p. 16 (HALKIN); vgl. SHaw (1990) 246 ff.; Mitchell (1999a) 156.

134 Mir. 28, 16f. 22-27; Hom. Od. X 80 ff.; Ramsay (1890) 380.

135 Stellen zur Tiertopik für Barbaren i.d. griech.-röm. Literatur bei SPEYER / OPELT (2001) $839 \mathrm{f}, 886 \mathrm{ff}$.

136 RougÉ (1966) 300; ebenso HeLlenKEMPER (1986) 633: „Die Eskalation der Auseinandersetzung fand eine neue Bewertung. Bei den Kirchenvätern Theodoret und Johannes Chrysostomos (Theodoret h.r. X 3; Joh. Chrysost. ep. ad Olympiadem IX 2; Hier. 
Zeitgenossen stellten sie in eine Reihe mit den von außerhalb kommenden Barbaren: Der Laterculus Veronensis zählte die Isaurier zu den Barbarenvölkern, die während der Kaiserzeit allgemein (sub imperatoribus) ,wie Pilze aus dem Boden schossen“. ${ }^{13}$ ? Der Chronist Marcellinus Comes nennt sie in einer Reihe mit den anderen Barbarenvölkern, welche noch im Jahr 441 das Reich heimsuchten. ${ }^{138}$ Der zu Beginn des 5 . Jahrhunderts schreibende Eunap nennt sie ,äußerst schrecklich"“. ${ }^{139}$ Der Barbarenbegriff, der zuvor zwischen ethnischer (ursprünglich lediglich „Nichtgriechen“) und kultureller Dimension differenzierte, war in der Spätantike verengt; seit 290 wird er in den Gesetzen synonym mit hostis verwandt. ${ }^{140}$

Die Geschichte in der Historia Augusta, daß die Usurpation des „Trebellianus“ dafür verantwortlich gewesen sei, daß die Isaurier als Barbaren angesehen wurden, ${ }^{141}$ läßt auf die Reflexion tatsächlicher Zustände zur Abfassungszeit schließen: Offenbar machte sich der Autor zu Beginn des 5. Jahrhunderts Gedanken, wie es dazu kommen konnte, daß die Isaurier sich von mitten im Reich ansässigen römischen Bürgern zu Barbaren wandeln konnten, die sich wie äußere Feinde verhielten. Tatsächlich war dies den weiträumigen Aufständen geschuldet, denn durch einzelne räuberische Aktionen, und seien sie noch so lästig, wird niemand zum Barbar oder zum Staatsfeind (hostis); er bleibt ein latro. Barbaren dagegen sind, wie oben dargelegt, Nichtrömer, Staatsfeinde, sie stehen außerhalb der innerhalb des zivilisierten orbis Romanus durch die römische Herrschaft garantierten Staatsordnung.

Dazu kommt, daß seit dem Ende des 3. Jahrhunderts mit der Rücknahme der Reichsgrenzen bestimmte, ehemals römische Gegenden wieder als Ausland (barbaricum) bezeichnet wurden, so das rechtsrheinische Gebiet, die mittlere und untere Donaugegend und Teile Africas. ${ }^{142}$

ep. 114, 1) sind die Isaurier Barbaren. Sie waren damit nicht mehr innere, sondern äußere Feinde." Hinzuzufügen ist die bei Theodoret und Philostorgios vertretende Barbarento-

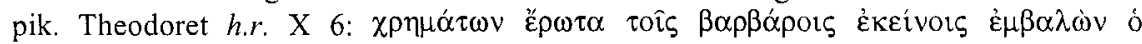

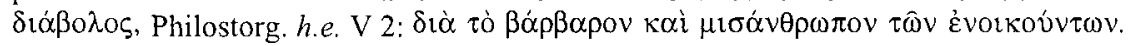

137 Laterculus Veronensis XIII 44 p. 252: gentes Barbarae, quae pullulaverunt sub imperatoribus.

138 Marc. com. s.a. 441: Persae, Saraceni, Tzanni, Isauri, Hunni finibus suis egressi Romanorum sola vastaverunt.

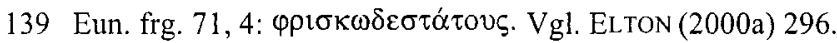

$140 C J$ VIII 50, 5; vgl. Zu den antiken Barbarenvorstellungen vgl. LECHNER (1954); VOGT (1967); NiPPEL (1990); in den Gesetzen Rugullis (1992) 39, 129; 21-26 zum literarischen Barbarenbegriff, insgesamt AUSENDA (1995); SPEYER / OPELT (2001); zu den barbarischen Invasionen vgl. die Arbeiten von GoFfART (1980). (1981). (1989).

141 SHA tyr. trig. 26, 6: denique post Trebellianum pro barbaris habentur; vgl. SHA Prob. 16, 5: barbarorum qui apud Isauros sunt (gleichzeitig ein Hinweis darauf, daß nicht alle Isaurier als Barbaren angesehen wurden).

142 SPEYER / OPELT (2001) 881f. 
Ein weiterer Faktor dürfte verstärkend auf diesen Prozeß der Barbarisierung der Isaurier gewirkt haben: Die Goten bewegten sich mittlerweile selbstverständlich und ungehindert auf dem Reichsboden hin und her; somit waren die Grenzen zwischen „inneren“ und „äußeren“ Barbaren längst verschwommen. Dies zeigte sich auch darin, daß unter Fravitta gotische Truppen gegen die Isaurier eingesetzt wurden, und dies bevor die Isaurier am Ende von Theodosius II. und Leos Regierungszeit gegen die Goten eingesetzt werden konnten. Lange bevor „die inneren Barbaren“ gegen die ,äußeren“ helfen konnten, ${ }^{143}$ mußten zuvor im 4. Jahrhundert die ,äußeren“ gegen die „inneren“ helfen.

Erst als die Isaurier als Barbaren angesehen wurden, konnten sie wiederum gleich den gotischen Föderaten ins Heer übernommen werden. Hier ist also eine Art Rückkopplung vonstatten gegangen; die Isaurier kamen gleichsam durch die Hintertür wieder zur Teilhabe am römischen Machtsystem. Dieser Prozeß erfolgte über die Erringung eines Kriegerstatus, den sie sich seit Beginn des 5. Jahrhunderts erarbeiteten, um gleich den Goten von der Etikettierung als Barbaren und Banditen wegzukommen. Für eine erneute Integration der Isaurier in die römische Gesellschaft war es nach den großen Aufständen des 4. Jahrhunderts gerade aus diesem Grunde zu spät; die flächendeckenden isaurischen Raubzüge waren nun zu tief im kollektiven Bewußtsein verankert, und im Gegensatz zu den Goten, die ständig Nachschub an Menschen aus dem Norden und Osten bekamen, waren sie als Einzelvolk zu isoliert. Bemerkenswert ist in diesem Zusammenhang der Korpsgeist der Isaurier, womöglich auch in Reaktion auf ihre nach den weiträumigen Aufständen hervorgerufene Ablehnung durch die restliche provinzialrömische und die gesamte konstantinopolitanische Bevölkerung. ${ }^{144}$ Trotz der Integrationsbemühungen auch gelehrter Isaurier blieb die Ablehnung bestehen. ${ }^{145}$ Daß die angeblich isaurische Herkunft des ikonoklastischen Kaisers Leo III. (717-741, Leo stammte in Wahrheit aus Nordsyrien) in den griechischen Quellen so betont wird, legt die Interpretation nahe, daß die Isaurier noch weit bis in die byzantinische Zeit hinein einen schlechten Ruf genossen. ${ }^{146}$

Für die von SHAW und RIESS vertretene Annahme, daß die Isaurier sich selbst völlig außerhalb des römischen Gemeinwesens verorteten, gibt es keinerlei Hinweis in den Quellen. Tendenziöse Autoren wie die Panegyriker des Anastasius hätten eine

143 DemandT (1989) 195; s.o. IV.2.4. Die Idee der ,inneren Barbaren“ war bis in die Neuzeit wirkungsmächtig; so sah bei der 1848er Revolution in Frankreich Auguste ROMiEU, L'ère des Césars, Paris 1850, die „inneren Barbaren“ am Werk, vgl. DEMANDT (1984) 512. LEPPIN (1998) 257 zählt sie mit den Goten zu den ,internal barbarians“.

144 S.u. Kap. V.2. u. HiLd / HellenKEMPER (1990) 38.

145 Vgl. Elton (2000a) 297.

146 S.u. Kap. VI.5. u. CAMERon / Herrin Parast. (1985) 168. 
derartige ablehnende Selbsteinschätzung der Isaurier wohl nicht unerwähnt gelassen, um ihnen (etwa analog zu den Juden) eben dies zum Vorwurf zu machen.

In einem wesentlichen Punkt unterschieden sich die isaurischen Banditen dabei von den Barbaren: Sie bedrohten das Reich nicht in seiner Substanz, denn sie hatten dazu nicht genügend Mittel, Truppen und Rückhalt in der eigenen Bevölkerung. Ihre großräumigen Aufstände konnten relativ rasch, wenn auch unter Aufbietung größerer Kräfte, mit militärischen Mitteln beendet werden. Gefährlich für den Fortbestand des Reiches wären sie nur geworden, wenn sie sich mit den gleichzeitig agierenden Goten verbündet hätten. Aufgrund ihrer Binnenlage hatten sie keinen Zugang zu den Reichsgrenzen und konnten deshalb keinen Kontakt zu den Goten, Hunnen oder Persern aufnehmen. Die Versuche von Zenos Gegner Illus, mit den Persern und Armeniern Verhandlungen gegen Zeno aufzunehmen, scheiterten. ${ }^{147}$

Zwar ist bisher deutlich geworden, daß der ländliche Raum in Isaurien in enger sozialer und ökonomischer Verflechtung mit den Städten stand. Gleichwohl läßt sich eine Stoßrichtung der Gewalt vom Land auf die Städte konstatieren: Die in Krisenzeiten zu kurz gekommene Landbevölkerung holte sich mit Gewalt den ihr von den Städten vorenthaltenen, oft von ihr selbst erwirtschafteten Überschuß. ${ }^{148}$ Mit anderen Worten: in Zeiten von Knappheit, die durch verschiedene Faktoren wie Einfälle von außen (wie es beim Einfall Shapurs I. oder den Goteneinfällen der Fall war) gepaart mit internem Mißmanagement (so im 4. Jh. unter Gallus) hervorgerufen wurde, kam es dann doch zu einem Konflikt zwischen Stadt und Land: den Polisbewohnern blieb angesichts des sozialen Gefälles immer noch ein Überschuß. Seit der allgemeinen Reichskrise des 3. Jahrhunderts ergaben sich für die Landbevölkerung ökonomische Schwierigkeiten. Die Regierung mußte vermehrt gegen die Goten kämpfen und konnte ihrer Versorgungsaufgabe in diesem strukturschwachen Landstrich nicht mehr nachkommen. So zogen es die Isaurier vor, sich Nahrungsmittel und Güter von den reichen Stadtbewohnern einfach zu nehmen.

Somit waren die Aufstände zwar unmittelbar ökonomisch motiviert, mittelbar jedoch wurden sie durch politische Faktoren hervorgerufen: Die erste Phase in der Geschichte der isaurischen Aufstände ist durch politischen Widerstand gekennzeichnet; die Unterwerfung unter Rom bot aber schließlich ökonomischen Aufschwung, folglich war die Region während der Kaiserzeit befriedet. Während der Krise des 3. Jahrhunderts verschlechterten sich die Verhältnisse, insbesondere nach dem sasanidischen Einfall. Wieder war die Ökonomie durch einen politischen Faktor beeinflußt. Mißmanagement und Goteneinfälle führten ab dem 4. Jh. schließlich zu einer Reihe

147 Vgl. LEE CAH XIV (2000) 50-53; Charlotte RoueCHÉ, ebda. 576.

148 So auch HOPWOOD (1986) 345f. gegen SHAW (1984) 42: „Banditry was the countryside's revenge upon the town-dweller for his exploitation of the countryside, not a coherent bid for national freedom". 
von Versorgungsengpässen, auf welche die isaurische (Land-) Bevölkerung mit Raubzügen reagierte. Der Krieg des Anastasius gegen die Isaurier ${ }^{149}$ schließlich hatte wiederum rein politische Ursachen.

Zusammenfassend läßt sich also feststellen: Die Geschichte der isaurischen Aufstände ist gekennzeichnet durch ein Wechselspiel zwischen politischen und ökonomischen Faktoren. Durchaus können auch ethnische Beweggründe mitgespielt haben, doch diese sind u. E. nicht konstitutiv für die Aufstände gewesen. Zurückzuweisen ist ein synchroner Ansatz, wie ihn SHAw verfolgt, denn die zeitlichen Umstände waren in dem hier zu untersuchenden Zeitraum eben doch grundverschieden. Für die These, daß isaurische Städter oder mächtige Figuren aus den Städten einen Aufstand gegen die römische Herrschaft angezettelt haben sollen, gibt es keine Quellengrundlage. Von der Belagerung Cremnas abgesehen, gab es auch zu keiner Zeit eine direkt aufständische Stadt in Isaurien. Hier wurde nicht eine aufständische Stadt belagert, sondern der darin befindliche Bandit und seine Anhänger, die diese Stadt als Geisel genommen hatten.

Große, in Belagerungskriege mündende Aufstände wie jener des Palfuerius und der eben geschilderte waren nach Verzweiflungstaten, die keinen Rückhalt in der städtischen Bevölkerung genossen, da sie sich gegen diese selbst und ihre Erwerbsgrundlage richteten. Die isaurischen Raubzüge waren ähnlich wie die BagaudenUnruhen in Gallien Ende des 3. Jahrhunderts durch ungleiche Verteilung der Ressourcen motiviert ${ }^{150}$ und hatten nichts mit einem nationalen Befreiungskampf gegen Rom zu tun. In diesem Sinne interpretierten die Nationalstaaten des 19. Jahrhunderts die jeweiligen Stammesaufstände gegen Rom. In den antiken Quellen dagegen sind die Isaurieraufstände immer als unmittelbare Ausbrüche von angeblich traditioneller Gewaltbereitschaft dargestellt. ${ }^{151}$ Wie es sich im übernächsten Kapitel zeigen wird, haben die isaurischen Mächtigen - ebenso wie die gotischen - eher das Ziel verfolgt, systemimmanent Karriere zu machen als eine abspalterische Bewegung um sich zu scharen. Der Isaurierkrieg des Anastasius allerdings war von Beginn an ein politischer, nachdem der Versuch der Integration gescheitert war. Doch dieser Aufstand stellt das einzige Beispiel für einen nicht-räuberischen Konflikt der Isaurier mit dem Imperium Romanum dar.

149 S.u. Kap. IV.4.

150 Santos Yanguas (1977); MatThews (1989) 366f. verweist auf die Schilderung Ammians, wie wichtig es für die Isaurier war, an Vorräte zu gelangen.

151 So z. B. Amm. XXVIII 6, 2: die Austurianer in Africa vivereque adsueti rapinis et caedibus. 